\title{
Restricted Acoustic Modal Analysis Applied to Internal Combustor Spectra and Cross-Spectra Measurements
}

Jeffrey Hilton Miles

Glenn Research Center, Cleveland, Ohio 


\section{NASA STI Program . . . in Profile}

Since its founding, NASA has been dedicated to the advancement of aeronautics and space science. The NASA Scientific and Technical Information (STI) program plays a key part in helping NASA maintain this important role.

The NASA STI Program operates under the auspices of the Agency Chief Information Officer. It collects, organizes, provides for archiving, and disseminates NASA's STI. The NASA STI program provides access to the NASA Aeronautics and Space Database and its public interface, the NASA Technical Reports Server, thus providing one of the largest collections of aeronautical and space science STI in the world. Results are published in both non-NASA channels and by NASA in the NASA STI Report Series, which includes the following report types:

- TECHNICAL PUBLICATION. Reports of completed research or a major significant phase of research that present the results of NASA programs and include extensive data or theoretical analysis. Includes compilations of significant scientific and technical data and information deemed to be of continuing reference value. NASA counterpart of peer-reviewed formal professional papers but has less stringent limitations on manuscript length and extent of graphic presentations.

- TECHNICAL MEMORANDUM. Scientific and technical findings that are preliminary or of specialized interest, e.g., quick release reports, working papers, and bibliographies that contain minimal annotation. Does not contain extensive analysis.

- CONTRACTOR REPORT. Scientific and technical findings by NASA-sponsored contractors and grantees.
- CONFERENCE PUBLICATION. Collected papers from scientific and technical conferences, symposia, seminars, or other meetings sponsored or cosponsored by NASA.

- SPECIAL PUBLICATION. Scientific, technical, or historical information from NASA programs, projects, and missions, often concerned with subjects having substantial public interest.

- TECHNICAL TRANSLATION. Englishlanguage translations of foreign scientific and technical material pertinent to NASA's mission.

Specialized services also include creating custom thesauri, building customized databases, organizing and publishing research results.

For more information about the NASA STI program, see the following:

- Access the NASA STI program home page at http://www.sti.nasa.gov

- E-mail your question via the Internet to help@sti.nasa.gov

- Fax your question to the NASA STI Help Desk at 301-621-0134

- Telephone the NASA STI Help Desk at 301-621-0390

- Write to:

NASA STI Help Desk

NASA Center for AeroSpace Information 7121 Standard Drive Hanover, MD 21076-1320 


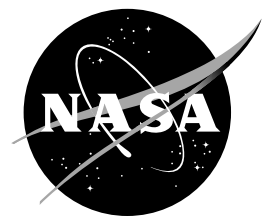

\section{Restricted Acoustic Modal Analysis Applied to Internal Combustor Spectra and Cross-Spectra Measurements}

Jeffrey Hilton Miles

Glenn Research Center, Cleveland, Ohio

Prepared for the

12th Aeroacoustics Conference

cosponsored by the American Institute of Aeronautics and Astronautics and Confederation of European Aerospace Societies

Cambridge, Massachusetts, May 8-10, 2006

National Aeronautics and

Space Administration

Glenn Research Center

Cleveland, Ohio 44135 
Trade names and trademarks are used in this report for identification only. Their usage does not constitute an official endorsement, either expressed or implied, by the National Aeronautics and Space Administration.

This work was sponsored by the Fundamental Aeronautics Program at the NASA Glenn Research Center.

Level of Review: This material has been technically reviewed by technical management.

Available from

NASA Center for Aerospace Information 7121 Standard Drive

Hanover, MD 21076-1320
National Technical Information Service 5285 Port Royal Road Springfield, VA 22161 


\title{
Restricted Acoustic Modal Analysis Applied to Internal Combustor Spectra and Cross-Spectra Measurements
}

\author{
Jeffrey Hilton Miles \\ National Aeronautics and Space Administration \\ Glenn Research Center \\ Cleveland, Ohio 44135
}

\begin{abstract}
A treatment of the modal decomposition of the pressure field in a combustor as determined by two Kulite pressure measurements is developed herein. It is applied to a Pratt \& Whitney PW4098 engine combustor over a range of operating conditions. For modes other than the plane wave the new part of the treatment is the assumption that there are distinct frequency bands in which the individual modes, including the plane wave mode, overlap such that if circumferential mode $m$ and circumferential mode $m-1$ are present than circumferential mode $m-2$ is not. Consequently, in the analysis used herein at frequencies above the first cut-off mode frequency, only pairs of circumferential modes are individually present at each frequency. Consequently, this is a restricted modal analysis. A new result is that the successful use of the same modal span frequencies over a range of operating conditions for this particular engine suggests that the temperature, $T$, and the velocity, $v$, of the flow at each operating condition are related by $c^{2}-v^{2}=$ a constant where $c$ is the speed of sound.
\end{abstract}

\section{Nomenclature}

$A \quad$ amplitude of clockwise pressure wave

$B$ amplitude of counter-clockwise pressure wave

$B_{e} \quad$ resolution bandwidth,Hz., $B_{e}=1 / T_{d}=r / N P=11.71875 H z$

$D \quad$ delay time $\tau$, sec. sometimes expressed as a number of samples, $D=\tau 48000$ )

$f \quad$ frequency, $\mathrm{Hz}$

$f_{c} \quad$ upper frequency limit, $f_{c}=1 / 2 \Delta t=r / 2, \mathrm{~Hz} .(24000 \mathrm{~Hz}$.

$G_{x x}(f)$ power spectral density

$G_{x y}(f)$ cross power spectral density

$j \quad$ positive imaginary square root of $-1, \sqrt{-1}$

$L_{c} \quad$ cost function

$L_{y} \quad$ number of frequencies, $f_{c} / \Delta f=N / 2(2048)$

$M \quad$ Mach number, $\bar{M}=\bar{u} \bar{c}$

$m$ mode number running index

$n \quad$ mode number running index

$n_{o \ell} \quad$ number of overlapped segments, with $50 \%$ overlap $n_{o \ell}=468$

$N P \quad$ segment length, number of data points per segment (4096)

$n_{d} \quad$ number of disjoint (independent) data segments/blocks, $n_{d}=B_{e} T_{\text {total }}=234$

$n_{0} \quad$ contaminating noise at station 0

$n_{\theta} \quad$ contaminating noise at station $\theta$

$P(f) \quad$ Fourier transform of $\mathrm{p}(\mathrm{t})$

$p(t) \quad$ pressure signal

$p_{k} \quad$ conversion constant, $10^{(171 / 20)} / 0.25$ 


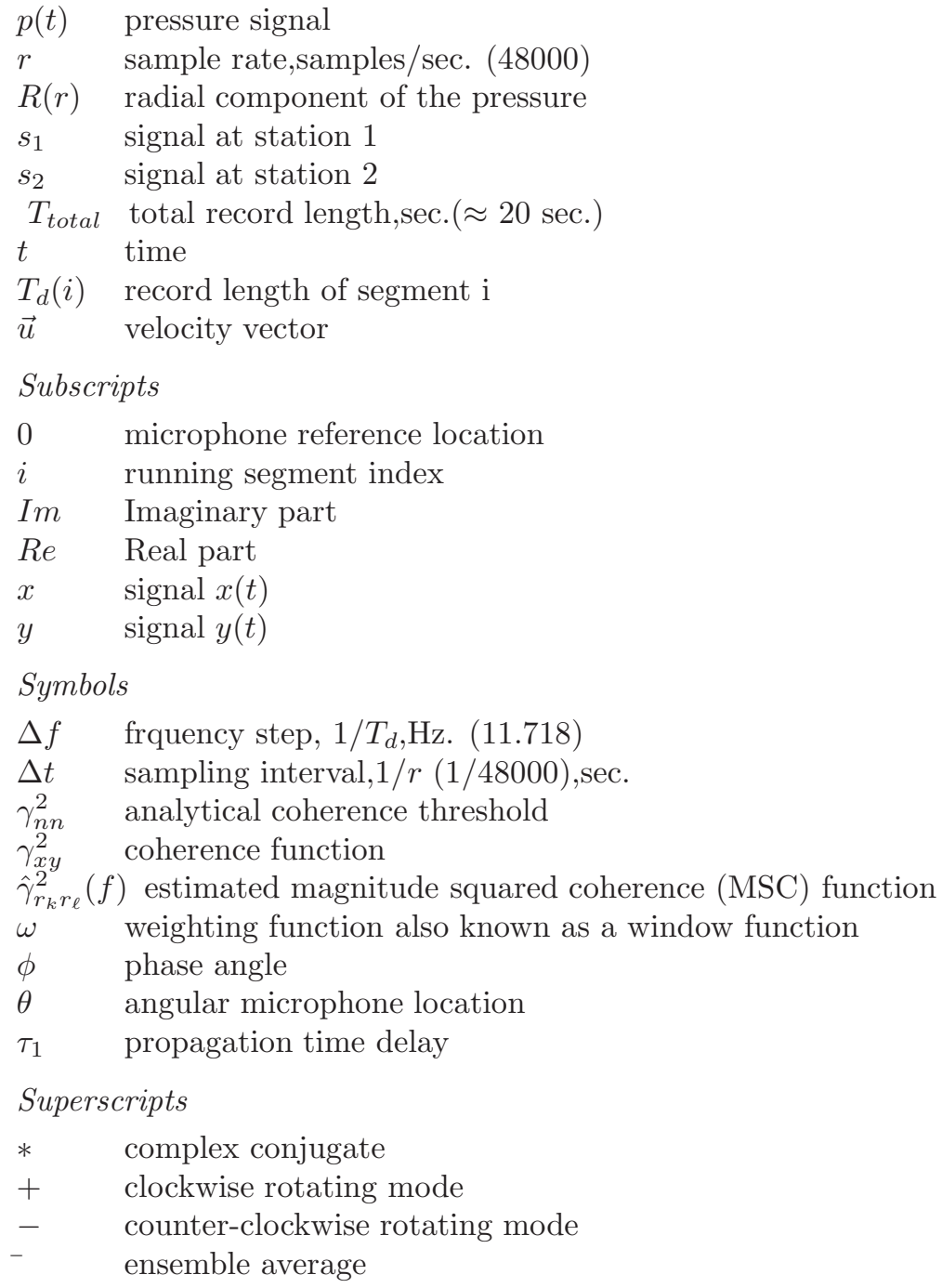

\section{INTRODUCTION}

To understand combustion noise measured in the far field of the PW4098 engine it is necessary to investigate and understand the pressure field in the annular combustor. The data analyzed is from a Pratt \& Whitney PW4098 engine. The test was conducted as part of phase 2 of the NASA Engine Validation of Noise Reduction Concepts (EVNRC) Program. For this test two Kulite pressure transducers were mounted in the combustor and four far field microphone were used. The coherent combustion noise seemed to have a modal pattern. Consequently, a restricted modal model was developed and tested to see if it was compatible with the available data. This work is reported herein. To be useful, the pressure field must be measured and analyzed in a manner consistent with the physics of the propagation process. A scheme that accomplishes this is discussed herein.

The Kulites failed during the test. Consequently, a sensor validation analysis was conducted by Miles. ${ }^{1}$ Results of this study were used to select the data evaluated herein. The Kulite signals and the far field microphone signals are used to obtain the far field coherent combustion noise output power and estimate the amount of coherent combustion noise that appears in the far field. ${ }^{2}$ A method for separating correlated noise sources (core noise) and uncorrelated noise sources (jet noise) in far field measurements of turbojet engine core noise using multiple microphones has also been developed and tested ${ }^{3}$.Results from the Kulite validation study $^{1}$ and this study of annular duct modes measured in the combustor by Kulite pressure transducers is used to interpret results of Miles. ${ }^{2,3}$

The pressure field inside an annular combustor is governed by the solution of an eigenvalue equation. The pressure is assumed to propagate as if it were in an infinite duct. Consequently, boundary conditions 
at the duct ends, reflections from the duct ends, and the possibility of standing waves are not considered. The pressure does propagates in particular bands identified by frequency ranges. The pressure pattern in a combustor is analyzed by breaking it up into the natural frequency bands of pressure propagation in an annular duct. Frequencies in the lowest band propagation in a plane wave mode. Higher bands move in propagating modes composed of eigenmode solutions to the annular duct eigenvalue equation governing wave propagation in an infinite annular duct with wall boundary conditions. The modes are composed of sinusoids in a circumferential direction and combinations of Bessel functions in a radial direction. The physics of pressure waves propagating in annular ducts is discussed by Tyler and $\operatorname{Sofrin}^{4}$ in a treatment of axial flow compressor noise and is presented by $\mathrm{Morse}^{5}$ as a problem on page 603. Each higher mode propagates only above its own cut-off frequency. It is expected that the pressure field in a combustion duct extends over a frequency range in which several modes are propagating. The distribution of energy in the frequency band for each propagating mode is unknown and might provide insight into the physics of the propagation process. Consequently, our understanding of the pressure field in an annular combustion would be increased if one could determine the distribution of energy between duct modes.

The use of normal mode theory to analyze the propagation of noise in ducts to find the optimal microphone positions in order to estimate sound power from sound-pressure measurements was studied by Dyer. ${ }^{6}$ This analysis was soon extended to look at spinning acoustic modes generated by fans. ${ }^{4,7-11}$ This analysis has also been used to look at the modal content of noise generated by a jet in a pipe. ${ }^{12-15}$ An acoustic modal analysis of a YF102 combustor installed in a ducted test rig was conducted by Karchmer ${ }^{16}$ who used the assumption of equal amplitude clockwise and counter-clockwise spinning modes in his analysis. He found that he only needed the circumferential modes 1 through 6 and the corresponding zeroth order radial modes in his reconstruction of the measured data. Acoustic modal analysis of the pressure field in the tailpipe of a turbofan engine was conducted by Krejsa and Karchmer $^{17}$ again the assumption of equal amplitude clockwise and counter-clockwise spinning modes was used in the data analysis.

Before duct mode theory was applied to study core noise other techniques were used. Core noise from a Pratt \& Whitney JT8D was studied by Grande ${ }^{18}$ using multiple microphone measurements to obtain auto and cross power spectra in a tail pipe extension as well as far field auto power spectra. Ten internal microphones were used to obtain measurements of narrow-band and one-third octave band pressure level spectra in a Avco Lycoming YF102 combustor by Wilson and O'Connel. ${ }^{19-21}$ Core noise in General Electric engines has been studied by Matta, Sandusky, and Doyle ${ }^{22}$ to relate performance with emissions and noise. Coherence functions and transfer functions were used by Doyle and Moore ${ }^{23}$ in a core noise investigation of the CF6-50 Turbofan Engine. They used five Kulite pressure transducers in the combustor, nine other internal sensors, and 15 far-field microphones. Doyle and Moore ${ }^{23}$ removed the time delays between the internal and far field signals using cross-correlation analysis. Doyle and Moore ${ }^{23}$ set the number of averages they used to 100 and as a consequence data below coherence function values of less than 0.1 are ignored. In this paper, the coherence function is plotted on a log amplitude scale since the coherence floor is near 0.01. Doyle and Moore ${ }^{23}$ try to identify the source location from vectoring of cross-correlation time delays and do not do a model study. However, examination of internal coherence and transfer functions plots indicate that combustion modes might be present. In addition, Doyle and Moore $^{23}$ do state that the appearance of a double peak with positive and negative time delays in some of the cross-correlation plots suggest that waves are moving circumferentially around the combustor.

The problem of mode propagation in an annular combustor is complex due to the presence of high speed flows and temperature gradients. The results given here are limited to using circumferential modes which resemble plane waves and the plane wave mode to replicate the measurements. To analyze the pressure distribution in a duct into its modes, it is necessary to be able to measure the relationships among the pressures at many different points. However, for this test measurements were available at only two points. Consequently, in this paper we only investigate the feasibility of using a restricted pressure modal model to replicate the single measured relationship.

The investigation discussed will:

- Show the Kulite instrumentation was functioning.

- Provide evidence the peaks and dips in the measured auto-spectra and cross-spectra magnitudes are due to duct propagation modes rather than a fluctuating pressure generating mechanism.

- Identify the energy distribution in the plane wave mode. 


\section{PW4098 Engine at C-11 Stand for EVNRC Phase 2 Tests}

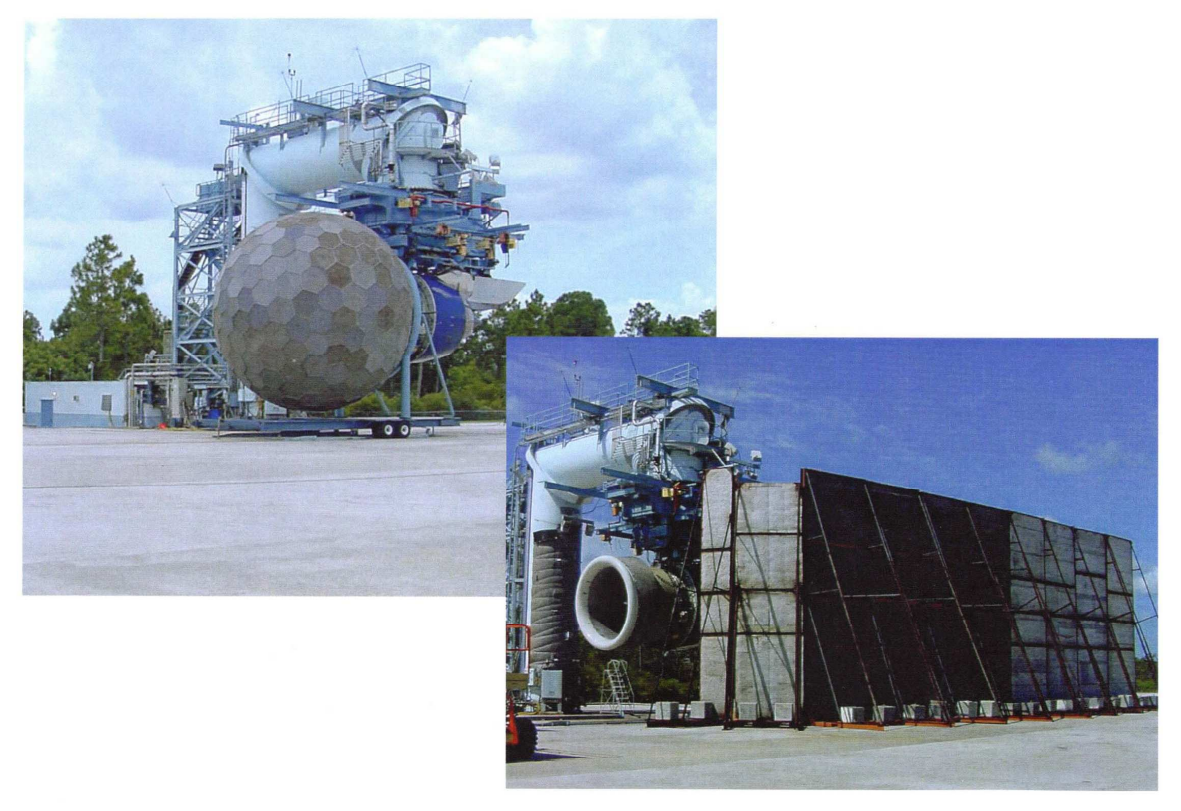

Figure 1. Pratt \& Whitney test stand C11, West Palm Beach Florida, with PW4098 engine and attached acoustic inflow control device also with and without aft acoustic barrier walls for EVNRC Phase 2 tests. 
- Examine the validity of the assumption that one has equal amplitude clockwise and counter-clockwise spinning modes.

- Test the idea that the data can be reconstructed using the first few circumferential modes, $m=1, m=$ $2, m=3 \ldots$ and the corresponding zeroth order radial modes $\mu=0$.

- Determine the energy distribution in each band of frequencies composing a propagation mode

\section{Experiment}

The two Kulite pressure measurements made in a Pratt \& Whitney PW4098 combustor will be discussed next. The measurements were made in a study of aircraft engine core noise conducted as part of the NASA Engine Validation of Noise Reduction Concepts (EVNRC) Program. The Kulite at $127^{\circ}$ is identified as Kulite 1 and produces a pressure signal, $p_{0}(t)$ while the other at $337^{\circ}$ is identified as Kulite 2 and produces a pressure signal, $p_{\theta}(t)$. Kulite angles are measured clockwise from top dead center viewed from the rear. The combustion chamber is annular. The PW4000 was fitted with 24 injectors. ${ }^{24}$ Fig. 1 on the preceding page shows the test stand. The spectral estimate parameters are shown in table 1 on the next page The signal processing algorithms used were written in Fortran. They are based on subprogram modules developed by Stearns and David. ${ }^{25}$ They were modified for this project to provide for time delay selection. In the calculations

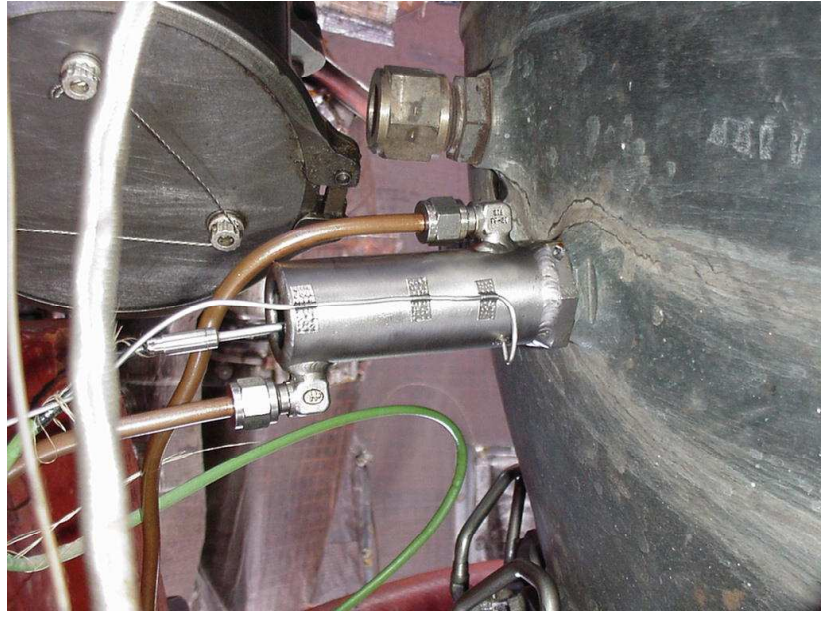

Figure 2. Kulite hardware mounted on PW4098 turbofan engine at Pratt \& Whitney test stand C11, West Palm Beach Florida for EVNRC Phase 2 tests. the segments were overlapped by 50 percent. Fig. 2 shows the Kulites mounted in the combustor with the water cooled jackets. Ten sets of data were analyzed. This paper shows results from three sets of combustor measurements made on the first test day. The values of N1 CORR. used are: $1622 \mathrm{rpm}, 1750 \mathrm{rpm}$, and $1900 \mathrm{rpm}$.

\section{Analysis}

\section{A. Measured Auto-Spectra and Cross-Spectra}

For discrete time signals the computation procedure is as follows. The total record length $T_{\text {total }}$ for received signals $p_{\theta}(t)$ and $p_{0}(t)$ is divided into $n_{d}$ disjoint (independent) data segments/blocks, each of length $T_{d}=$ $T_{\text {total }} / n_{d}$ so that there is an ensemble of measurements $\left\{p_{\theta i}(t)\right\}$ and $\left\{p_{0 i}(t)\right\}$

$$
\begin{aligned}
& \left\{p_{\theta i}(t)\right\}=\left\{s_{2}(t)+n_{\theta}\right\}_{i}, \quad i=1, \cdots, n_{d} \quad 0 \leq t \leq T \\
& \left\{p_{0 i}(t)\right\}=\left\{s_{1}(t)+n_{0}(t)\right\}_{i}, \quad i=1, \cdots, n_{d} \quad 0 \leq t \leq T
\end{aligned}
$$

where $n_{\theta}(t)$ and $n_{0}(t)$ are the contaminating noise at receiver location 1 . Angular positions, $\theta$, are relative to Kulite 1 at $227^{\circ}$ which was used as an arbitrary reference $\theta=0^{\circ}$ location. The relative angular location of Kulite 2 at $337^{\circ}$ is then $\theta=210^{\circ}$.

Using notation similar to that used by Piersol ${ }^{26}$ the one sided auto-spectra, $\bar{G}_{00}(f), \bar{G}_{\theta \theta}(f)$ and the crossspectrum, $\bar{G}_{0 \theta}(f)$ are estimated for a given pair of random pressure signals, at a frequency $\mathrm{f}$ as

$$
\begin{aligned}
\bar{G}_{00}(f) & =\overline{P_{0}(f) P_{0}^{*}(f)} \\
& =\frac{2}{T_{d} n_{d}} \sum_{i=1}^{n_{d}} P_{0 i}^{*}(f) P_{0 i}(f)
\end{aligned}
$$




$$
\begin{aligned}
\bar{G}_{\theta \theta}(f) & =\overline{P_{\theta}(f) P_{\theta}^{*}(f)} \\
& =\frac{2}{T_{d} n_{d}} \sum_{i=1}^{n_{d}} P_{\theta i}^{*}(f) P_{\theta i}(f) \\
\bar{G}_{0 \theta}(f) & =\overline{P_{0}(f) P_{\theta}^{*}(f)} \\
& =\frac{2}{T_{d} n_{d}} \sum_{i=1}^{n_{d}} P_{\theta i}^{*}(f) P_{0 i}(f)
\end{aligned}
$$

where the - indicates an ensemble average and $P_{\theta i}^{*}(f)$ and $P_{0 i}(f)$ are the Fourier transform of the measured pressure signals at the reference position and at the angle $\theta$. The ${ }^{*}$ designates the complex conjugate. The Fourier transforms used are windowed Fourier transforms:

$$
\begin{aligned}
\omega(\tau) & =\left(1-\frac{|\tau|}{T_{d}}\right) \\
P_{\theta i}^{*}(f) & =\int_{0}^{T_{d}(i)} \omega(\tau) p_{\theta i}(\tau) e^{j 2 \pi f \tau} d \tau \\
P_{0 i}(f) & =\int_{0}^{T_{d}(i)} \omega(\tau) p_{0 i}(\tau) e^{-j 2 \pi f \tau} d \tau
\end{aligned}
$$

where $\omega(t a u)$ is a weighting function also known as a window function. This approach is used in evaluating spectra of random data (see Stearns ${ }^{27}$ section 15.6). In practice these quantities are computed using a Fast Fourier transform. The estimate $\bar{G}_{0 \theta}(f)$ is a complex number such that

$$
\bar{G}_{0 \theta}(f)=\bar{G}_{R e}(f)-j \bar{G}_{I m}(f)=\left|\bar{G}_{0 \theta}(f)\right| e^{-j \bar{\phi}_{0 \theta}(f)}
$$

where

$$
\begin{aligned}
\left|\bar{G}_{0 \theta}(f)\right| & =\left[\bar{G}_{R e}^{2}(f)+\bar{G}_{I m}^{2}(f)\right]^{1 / 2} \\
\bar{\phi}_{0 \theta}(f) & =\tan ^{-1}\left[\frac{\bar{G}_{I m}(f)}{\bar{G}_{R e}(f)}\right]
\end{aligned}
$$

From Piersol ${ }^{26}$ and Stearns and David ${ }^{25}$ the spectral estimate will be at discrete frequencies separated by $\Delta f=1 / T_{d}$. For digital data processing with a sampling rate, $r$, and $N P$ data points per segment, the length of each segment is $T_{d}=N / r$ seconds. The sampling interval is $\Delta t=1 / r$. Consequently, $\Delta f=1 /(\Delta t N P)$ and the upper frequency limit is $f_{c}=1 /(2 \Delta t)=r / 2$. The, number of frequencies for nonredundant spectral estimates is $L_{y}=f_{c} / \Delta f=N / 2$. The spectral estimate parameters are shown in Table 1.

The signal processing algorithms used were written in Fortran based on subprogram modules ${ }^{25}$ which were modified for this project to be in Fortran 90 form. In addition, the processing scheme was changed to permit delaying one time sequence with respect to another. For these computations, a data segment/block record length of $T_{d}=4096 / 48000=0.08533 \mathrm{sec}$. seconds was used and the number of disjoint data segments $/$ blocks was $n_{d}=234$. Consequently, total record length was $T_{d} n_{d} \approx 20 \mathrm{sec}$. . The analysis was done with 50 per cent over lap so $n_{o l} \approx 468$.

The coherence is given by

$$
\gamma_{0 \theta}^{2}(f)=\frac{\left|G_{0 \theta}(f)\right|^{2}}{G_{00}(f) G_{\theta \theta}(f)}
$$


The measured coherence calculated using segments overlapped by $50 \%$ is given by

$$
\bar{\gamma}_{0 \theta}^{2}(f)=\frac{\left|\sum_{i=1}^{n_{o \ell}} P_{\theta i}^{*}(f) P_{0 i}(f)\right|^{2}}{\sum_{i=1}^{n_{o \ell}}\left|P_{0 i}(f)\right|^{2} \sum_{i=1}^{n_{o \ell}}\left|P_{\theta i}(f)\right|^{2}}
$$

Given measurements from two sensors to examine, we can say a sensor is providing an incorrect signal if the signals are uncorrelated with each other or the correlation changes abruptly in some irregular fashion. A procedure developed by Miles ${ }^{1}$ based on the concept of aligned and unaligned coherence is used to determine the validity of the signals from the Kulites. Miles ${ }^{1}$ shows that by comparing a coherence function calculated using aligned and unaligned time histories one may decide if the signals from two sensors are uncorrelated or have changed in some irregular fashion. The Kulite pressure data set examined in this paper was selected using this procedure. This procedure compares the normal measured coherence, $\bar{\gamma}_{0 \theta}^{2}(f)$, called the aligned coherence, with one calculated by time delaying one signal by an amount $D$ greater than the segment/block interval $T_{d}$. The value of $D$ is chosen so that the two signals are not in the same segment/block interval, $T_{d}$ and consequently appear to the processing procedure to be uncorrelated. For this study a value of $D$ approximately 1.5 times the segment/block interval is used. The measured unaligned coherence, $\bar{\gamma}_{0 \theta}^{2}(f, D)$ is not zero. Even if no tones are present, the coherence of two disjoint (incoherent/independent) random noise records has a value dependent on the number of independent data segments/blocks used to calculate the coherence, $n_{d}$. In Miles ${ }^{2}$ results were obtained from computer simulation that show good agreement with the theoretical estimate of the analytical coherence threshold

$$
\gamma_{n n}^{2}=1-(1-P)^{1 /\left(n_{d}-1\right)}
$$

where we use $P=0.95$ and $n_{d}=n_{o \ell}$. The coherence threshold $\gamma_{n n}^{2}$ is discussed by Carter, ${ }^{28,29}$ Halliday et. al. ${ }^{30}$ (page 247), and Brillinger ${ }^{31}$ (page 317). The coherence threshold $\gamma_{n n}^{2}$ has a value which is greater than $95 \%$ of the values of the coherence of two independent time series calculated using $n_{d}$ disjoint data segments/blocks. For the values shown in table 1 on the preceding page with a $50 \%$ overlap, a total record length, $T_{\text {Total }}$, of 20 seconds, and a resolution bandwidth, $B_{e}$, of $11.718 \mathrm{~Hz}$., the number of data segments/blocks is $n_{d}=2 \Delta f T_{\text {Total }} \approx 468$. The coherence of random noise for this case is $\gamma_{n n}^{2}=0.00639431$. The concept of aligned and unaligned coherence is discussed in more detail in Miles. ${ }^{2}$

In addition, if tones are present in the time signal they will be present in all ensembles averaged and appear in the unaligned and aligned coherence. In addition to aiding the identification of persistent tones, the unaligned coherence provides a reference coherence. Small values of the aligned coherence greater than the unaligned reference coherence can be easily identified as significant since one knows what the uncorrelated coherence looks like. However, the major support it provides is in determining if a sensor is providing a useful signal. If the aligned and unaligned coherence are similar than the two sensors are uncorrelated and one sensor has failed.

For the three cases discussed herein measured auto-spectra magnitudes and cross-spectra magnitudes and phase angles are shown in Fig. 3 on the next page. Both a measured and an unwrapped phase angle are shown. While the amplitudes of the cross-spectra are not remarkable, the cross spectral phases are quite notable in that the phase differences are not as predominantly either $0^{\circ}$ or $180^{\circ}$ as was found by Karchmer ${ }^{16}$ in his study of YF102 combustor modes. The presence of this feature in the YF102 phase spectra which is a characteristic of standing circumferential waves was found at all conditions tested by Karchmer. Consequently, in the PW4098 combustor the circumferential waves are not predominantly standing waves but are spiraling or spinning waves. The amplitudes of the cross-spectra and the coherence function do have a lumpy appearance which is characteristic of the presence of a modal structure.

In Bendat ${ }^{32}$ and in Piersol $^{26}$ the random error in the phase estimates due to statistical sampling is given in terms of the standard deviation of the estimated phase angle, $\bar{\theta}_{0 \theta}$, by

$$
\sigma\left[\bar{\theta}_{0 \theta}(f)\right] \approx \sin ^{-1}\left\{\frac{\left[1-\gamma_{0 \theta}^{2}(f)\right]^{1 / 2}}{\left|\gamma_{0 \theta}\right| \sqrt{2 n_{o \ell}}}\right\}
$$

where $\sigma\left[\bar{\theta}_{0 \theta}(f)\right]$ is measured in radians and as used herein $n_{o \ell}$ is selected to be the number of overlapped segments or blocks used in the spectral calculations. For the special case where the term in curly brackets is small Eq. 11 becomes 

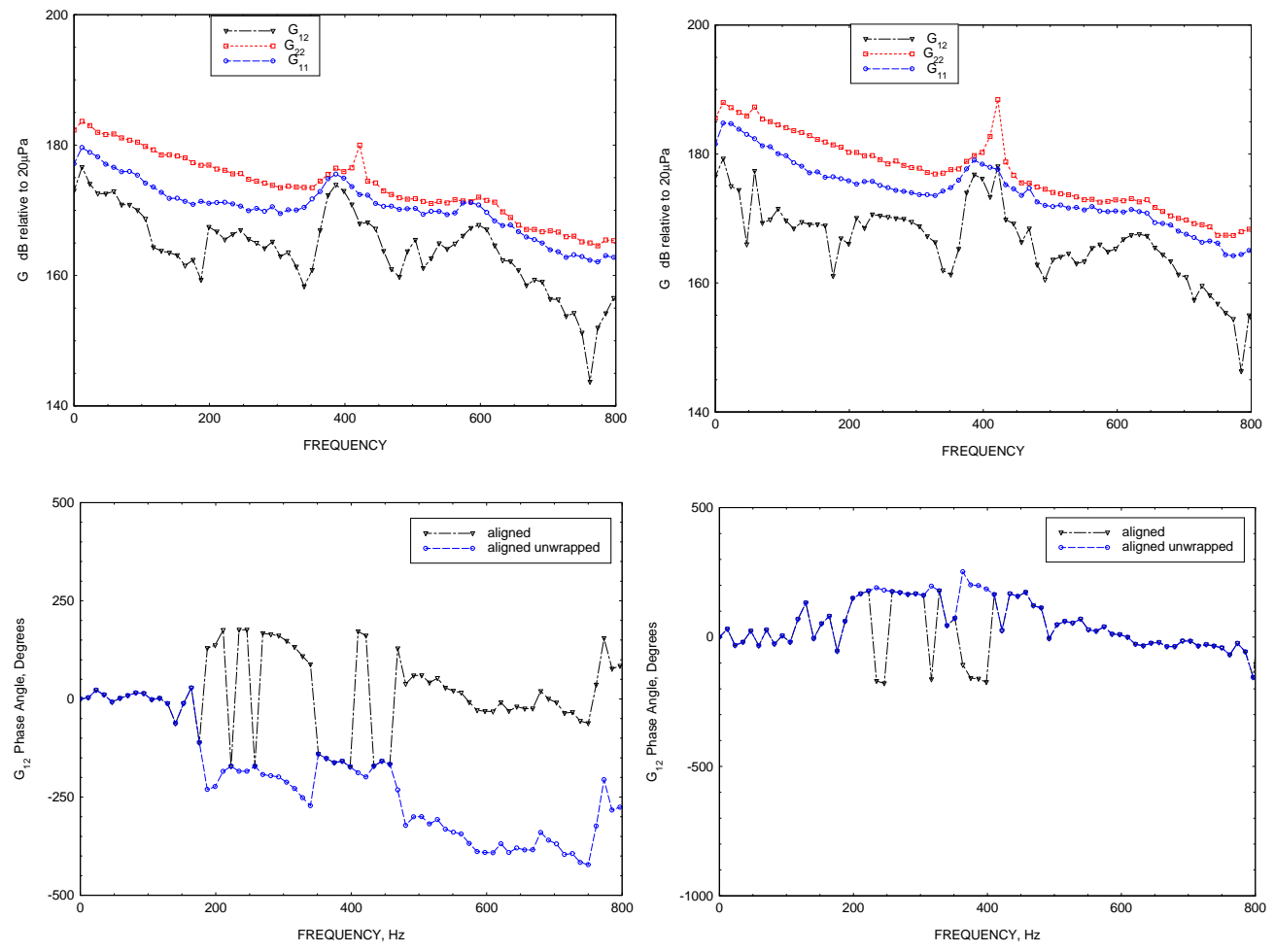

(a) $1622 \mathrm{rpm}$ ( N1 Corr )

(b) $1999 \mathrm{rpm}$ ( N1 Corr )
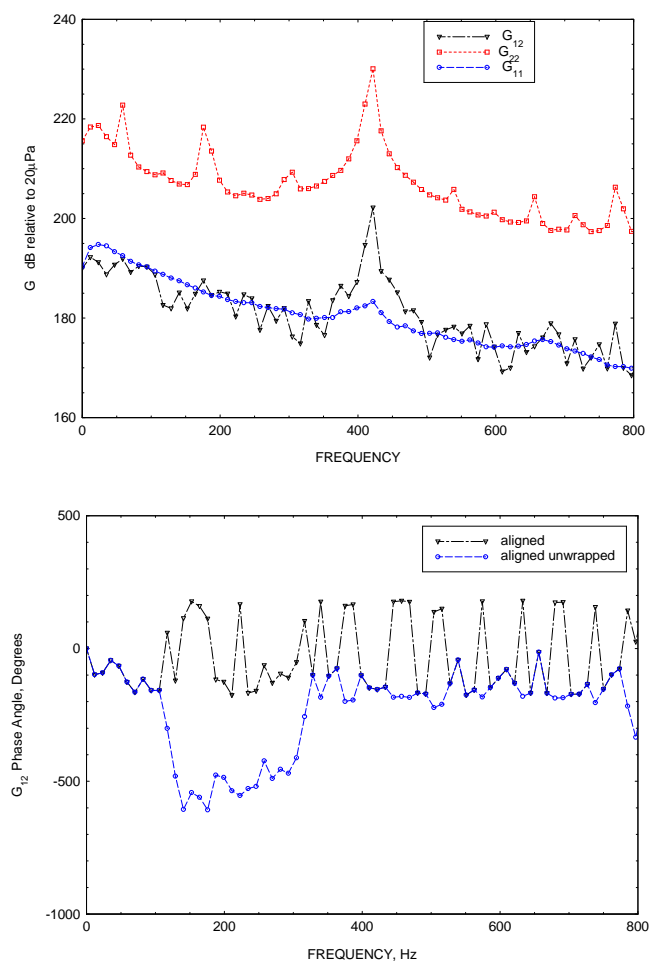

(c) $2600 \mathrm{rpm}$ ( N1 Corr )

Figure 3. Auto-spectrum magnitude for Kulite (1) at 127 degrees and Kulite (2) at 337 degrees and crossspectrum magnitude and phase between Kulite (1) and Kulite (2). 


$$
\sigma[\bar{\theta}(f)] \approx \frac{\left[1-\gamma_{0 \theta}^{2}(f)\right]^{1 / 2}}{\left|\gamma_{0 \theta}\right| \sqrt{2 n_{o \ell}}}
$$

where for the unknown coherence $\gamma_{0 \theta}^{2}(f)$ the estimated coherence $\bar{\gamma}_{0 \theta}^{2}(f)$ from Eq. 9 is used. A plot of the standard deviation of the phase angle in degrees verses coherence is shown in 4 for $n_{o \ell}=468$.

When the coherence is greater than 0.02, Fig. 3 shows the standard deviation should be less than 13 degrees for $n_{o \ell}=468$. This is accurate enough if no spinning modes are present and the phase angle difference is either $0^{\circ}$ or $180^{\circ}$.

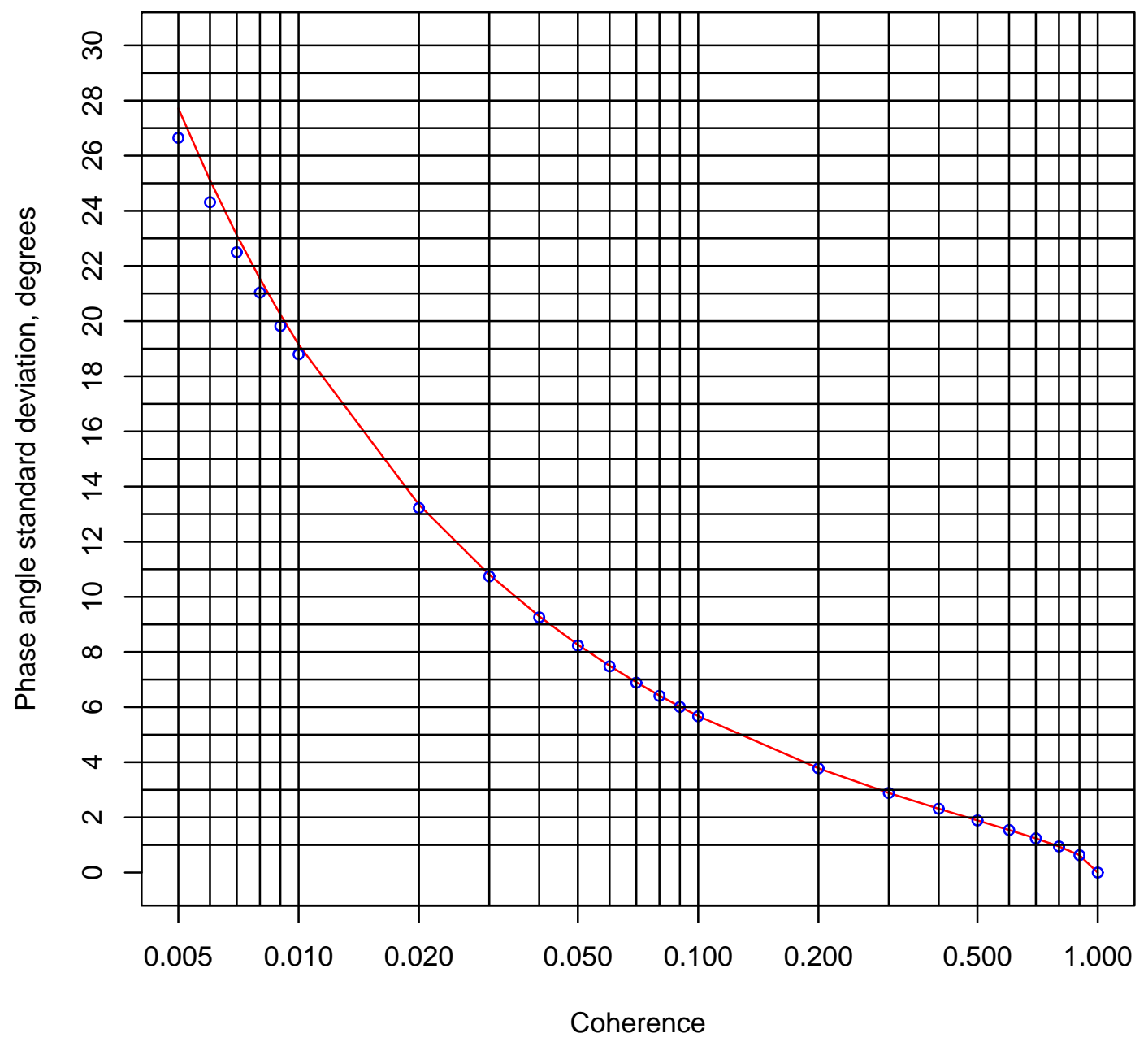

Figure 4. Standard deviation of phase angle of $G_{0 \theta}$ based on $\gamma_{0 \theta}^{2}$ and $n_{o \ell}$. 
The measured aligned and unaligned coherence is shown in Fig. 5 for the three cases. While many coherence values are less than 0.1 the coherence is still valid. As discussed, the aligned coherence is grater than the unaligned coherence indicating the coherence is not due to random noise. The random noise coherence value is the unaligned coherence value. In addition, the measured unaligned coherence is generally below the $95 \%$ confidence value for the analytic coherence threshold of the random noise which is $\gamma_{n n}^{2}=0.00639431$ and is shown as the black line in Fig. 5(a) through 5(c). Fig. 5(c) shows that at this 2600 rpm test point near the end of the test run the measured coherence is the same as the random noise coherence. Looking at Fig. 3(c) we see that Kulite 2 has failed and the measured auto spectrum $G_{22}$ has an incorrect value. Using a statistical coherence threshold procedure discussed by Miles ${ }^{1}$ each test point was examined for validity and sensor degradation. Initially runs with $\mathrm{rpm}$ in the range of 1622 to 2400 were used in the modal analysis However, eventually runs with $2304 \mathrm{rpm}$ and $2400 \mathrm{rpm}$ were discarded. This left eight cases.

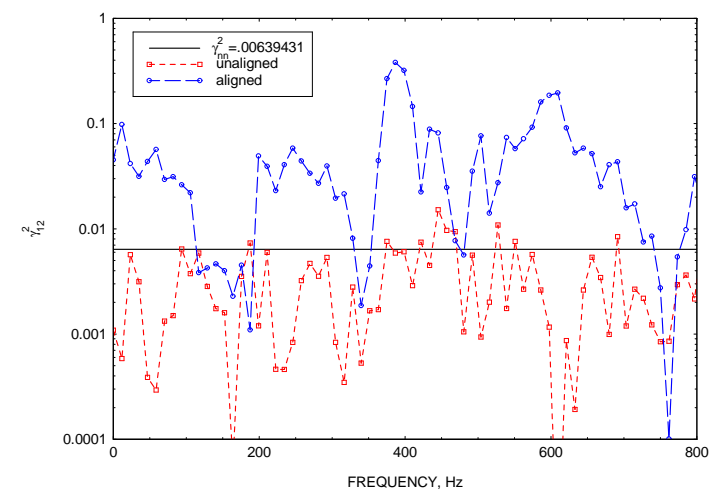

(a) $1622 \mathrm{rpm}$ ( N1 Corr )

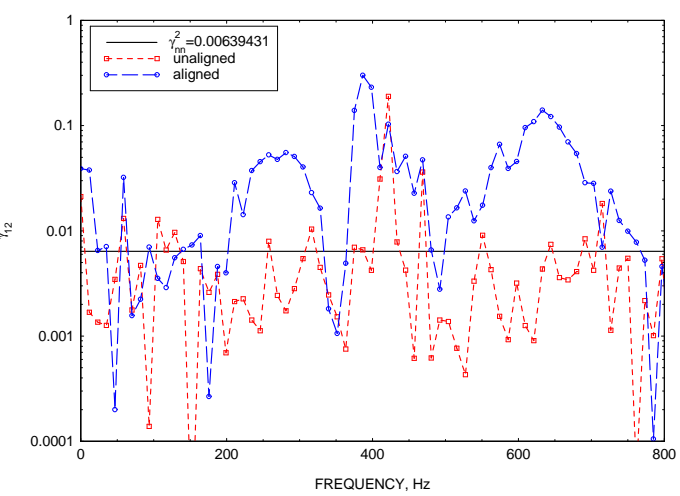

(b) $1999 \mathrm{rpm}$ ( N1 Corr )

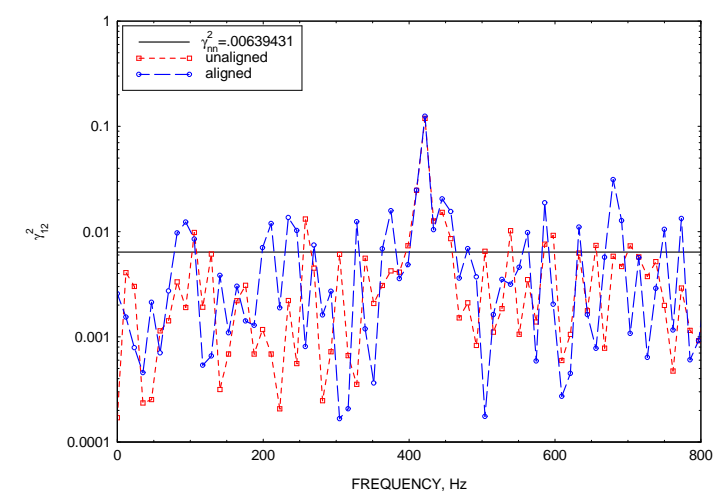

(c) $2600 \mathrm{rpm}$ ( N1 Corr )

Figure 5. Comparison of aligned and unaligned coherence between combustor Kulite (1) at 127 degrees and combustor Kulite (2) at 337 degrees.

\section{B. Modal Decomposition Method}

The approach implemented here is based on the mathematical modal decomposition technique used by Karchmer. ${ }^{16}$ Technical details on the eigenvalue problem and solution are given in Appendix A. The problem solved includes the mean flow. A new result given in Appendix A is that the successful use of the same modal span frequencies over a range of operating conditions for this particular engine suggests that the temperature, $T$, and the velocity, $v$, of the flow at each operating condition are related by $c^{2}-v^{2}=$ a constant where $\mathrm{c}$ is the speed of sound. The use of modal span frequencies will be discussed in the next section.

The analysis starts by assuming that a randomly occurring instantaneous pressure disturbance produced 
by the combustion process sends a clock-wise and counter clockwise pressure wave moving around the annulus. At an angle $\theta$ the two waves add to produce the resulting pressure written in terms of annular duct modes:

$$
\begin{aligned}
p_{\theta}(t) & =P_{\theta}^{+}(t)+P_{\theta}^{-}(t) \\
& =e^{j \omega t} \sum_{m=0}^{M-1}\left[A_{m} e^{j\left(\phi_{m}-m \theta\right)}+B_{m} e^{j\left(\phi_{m}+m \theta\right)}\right]
\end{aligned}
$$

where $A_{m}$ and $B_{m}$ are the amplitudes of the clock-wise and counter-clockwise pressure waves associated with the lowest radial order of the $m$ th circumferential mode, $\phi_{m}$ is the phase of the $m$ th mode, $j=\sqrt{-1}$ and $\mathrm{M}$ is the total number of modes present. Note higher order radial modes are neglected.

At the reference angle where $\theta=0$

$$
\begin{aligned}
p_{0}(t) & =P_{0}^{+}(t)+P_{0}^{-}(t) \\
& =e^{j \omega t} \sum_{m=0}^{M-1}\left[A_{m}+B_{m}\right] e^{j \phi_{m}}
\end{aligned}
$$

Consequently, the cross-spectrum $P_{0} P_{\theta}^{*}$ is

$$
\begin{aligned}
P_{0} P_{\theta}^{*}= & \sum_{m=0}^{M-1}\left[A_{m}+B_{m}\right] e^{j \phi_{m}} \\
& \sum_{n=0}^{N-1}\left[A_{n} e^{-j\left(\phi_{n}-n \theta\right)}+B_{n} e^{-j\left(\phi_{n}+n \theta\right)}\right] \\
= & \sum_{m=0}^{M-1} \sum_{n=0}^{N-1}\left(A_{m} A_{n}+B_{m} B_{n}\right) e^{j\left(\phi_{m}-\phi_{n}+n \theta\right)} \\
& +\sum_{m=0}^{M-1} \sum_{n=0}^{N-1}\left(B_{m} B_{n}+A_{n} B_{m}\right) e^{j\left(\phi_{m}-\phi_{n}-n \theta\right)}
\end{aligned}
$$

After taking the ensemble average the products become correlations. The assumption is now made that the modes are independent. Consequently, the cross-correlations vanish. All terms in the averaged version of Eq. ( 15 ) for which $m \neq n$ vanish.

$$
\begin{aligned}
\overline{P_{0} P_{\theta}^{*}}= & \sum_{m=0}^{M-1}\left(\overline{A_{m}^{2}}+\overline{B_{m} A_{m}}\right) e^{j m \theta} \\
& +\sum_{m=0}^{M-1}\left(\overline{B_{m}^{2}}+\overline{A_{m} B_{m}}\right) e^{-j m \theta}
\end{aligned}
$$

Using the definition $e^{j m \theta}=\cos (m \theta)+j \sin (m \theta)$ and noting that

$$
\overline{\left(A_{m}+B_{m}\right)^{2}}=\overline{A_{m}^{2}}+2 \overline{B_{m} A_{m}}+\overline{B_{m}^{2}}
$$

it follows that Eq. (16) becomes

$$
\begin{aligned}
\overline{P_{0} P_{\theta}^{*}}= & \sum_{m=0}^{M-1} \overline{\left(A_{m}+B_{m}\right)^{2}} \cos m \theta \\
& +j \sum_{m=0}^{M-1}\left(\overline{A_{m}^{2}}-\overline{B_{m}^{2}}\right) \sin m \theta
\end{aligned}
$$




$$
\begin{aligned}
& =\overline{P_{0} P_{\theta}^{*}} R_{e}+j \overline{P_{0} P_{\theta}^{*}} \\
& =\left|\overline{P_{0} P_{\theta}^{*}}\right| e^{j \phi_{\theta \theta}} \\
\left|\overline{P_{0} P_{\theta}^{*}}\right| & \left.=\left[\left(\overline{P_{0} P_{\theta}^{*}}\right)_{R e}^{2}\right)+\left(\overline{P_{0} P_{\theta}^{*}}\right)_{I m}^{2}\right]^{1 / 2}
\end{aligned}
$$

Equation ( 18 ) is the general expression for the complex cross-spectrum between the pressure measured at the reference position and the pressure measured at a given angle $\theta$ relative to the reference position. The magnitude is given by Eq. ( 19 ).

The phase of this cross-spectrum, then, is

$$
\begin{aligned}
\phi_{0 \theta}\left(A_{m}, B_{m}\right) & =\tan ^{-1} \frac{\left(\overline{P_{0} P_{\theta}^{*}}\right)_{I m}}{\left(\overline{P_{0} P_{\theta}^{*}}\right)_{R e}} \\
& =\tan ^{-1} \frac{\sum_{m=0}^{M-1}\left(\overline{A_{m}^{2}}-\overline{B_{m}^{2}}\right) \sin m \theta}{\sum_{m=0}^{M-1} \overline{\left(A_{m}+B_{m}\right)^{2}} \cos m \theta}
\end{aligned}
$$

Table 2. Mode span

\begin{tabular}{|l|l|l|r|r|}
\hline Mode, $\mathrm{m}$ & Low index & High index & Low frequency, $\mathrm{Hz}$ & High frequency, $\mathrm{Hz}$ \\
\hline \hline 0 & 0 & 15 & 0 & 175.78125 \\
\hline 1 & 16 & 28 & 187.50000 & 328.12500 \\
\hline 2 & 29 & 46 & 339.84375 & 539.06250 \\
\hline 3 & 47 & 71 & 550.78125 & 832.03125 \\
\hline 4 & 72 & 73 & 843.75000 & 855.46875 \\
\hline 5 & 74 & 75 & 867.18750 & 878.90625 \\
\hline 6 & 76 & 77 & 890.62500 & 902.34375 \\
\hline \hline
\end{tabular}

\section{The restricted modal model}

Equation ( 18 ) and ( 20 ), together with the single cross-spectrum measurement from the PW4098 combustor, form the basis of the modal analysis feasibility study conducted herein. The approach used by Karchmer ${ }^{16}$ assumed that only the first six modes make a significant contribution to the pressure field in the combustor over the frequency range of interest in core noise studies. Consequently, to determine six unknown values of $A_{m}$ and six unknown values of $B_{m}$ one would use measurements of cross-spectrum magnitude and phase at twelve positions $(\theta)$ to create twelve equations so that one could solve for twelve unknowns.

However, in the study of the YF102 combustion modes Karchmer $^{16}$ found that the measured crossspectrum phase was either $0^{\circ}$ or $180^{\circ}$ depending on the sign of the real part of the cross spectrum. Consequently, from Eq. ( 20 ) the imaginary part of the cross spectrum is zero and in evaluating modal constants $A_{m}$ and $B_{m}$ he could assume $A_{m}=B_{m}$. Consequently, he could then infer that the sources are such that an instantaneous pressure disturbance created in the combustor sends equal amplitude clockwise and counter-clockwise pressure waves traveling circumferentially around the combustor annulus. This creates a standing circumferential pressure wave rather than a rotating or spinning circumferential pressure wave. For this case, the Kulite cross-spectra phase angles would have only values of 0 degrees or 180 degrees. Using this information one only needs measurements of cross spectrum magnitude at six position $(\theta)$ to create six equations so that one can solve for six unknown values of $A_{m}$ where $A_{m}=B_{m}$. Consequently, the first assumption made herein is that for this case the pressure is a standing wave and $A_{m}=B_{m}$. This is done even though some of the phase angles measured seem to have intermediate values.

The theory of mode propagation and the measurements by Kerschen and Johnston indicate that modes cut-on at particular frequencies. ${ }^{12-15}$ Consequently, the second assumption made herein is that one can choose cut-on frequencies for each mode used to model the system. The selected mode span frequencies are shown in Table 2. 
Examination of the modal decomposition done by Karchmer ${ }^{16}$ shown in Fig. 7 in his paper indicates that one may easily assume that only the most recent cut-on mode is important. Consequently, in this model when mode $m$ is cut-on then the amplitude of the $m-2$ mode is set to zero. At any frequency only the amplitude of mode $m$ and mode $m-1$ must be found. This will be designated using the notation $\sum_{m, m-1}$. Due to this restriction on the modes, the term restricted modal model is used herein. The final assumption is that the reconstructed model auto spectrum, $\left|\overline{P_{0} P_{0}^{*}}\right|^{2}$ should be less than or equal to the measured auto-spectrum.

Using these assumptions we have a measurement of cross spectrum magnitude and phase and two equations and two unknowns, $A_{m}(f)$ and $A_{m-1}(f)$ at each frequency. The two equations are written in complex notation as

$$
\left|\bar{G}_{0 \theta}(f)\right| e^{j \bar{\phi}_{0 \theta}(f)}=\left|\overline{P_{0} P_{\theta}^{*}}\left(A_{m}(f), A_{m-1}(f)\right)\right| e^{j \bar{\phi}_{0 \theta}\left(A_{m}(f), A_{m-1}(f)\right)}
$$

where

$$
\begin{aligned}
& \overline{P_{0} P_{\theta}^{*}\left(A_{m}(f), A_{m-1}(f)\right)}=\sum_{m, m-1} 4 \overline{A_{m}^{2}} \cos (m \theta) \\
& \left|\overline{P_{0} P_{\theta}^{*}\left(A_{m}(f), A_{m-1}(f)\right)}\right|^{2}=\left\{\sum_{m, m-1} 4 \overline{A_{m}^{2}} \cos (m \theta)\right\}^{2} \\
& \bar{\phi}_{0 \theta}(f)=\overline{\phi_{0 \theta}\left(A_{m}, A_{m-1}\right)}=\left\{\begin{array}{lllll}
0^{\circ} & \text { or } & 360^{\circ} & : & \overline{P_{0} P_{\theta}^{*}}>0 \\
& & 180^{\circ} & : & \overline{P_{0} P_{\theta}^{*}}<0
\end{array}\right. \\
& \left|\overline{P_{0} P_{0}^{*}\left(A_{m}(f), A_{m-1}(f)\right)}\right|^{2}=\left\{\sum_{m, m-1} 4 \overline{A_{m}^{2}}\right\}^{2}
\end{aligned}
$$

where a mode $\mathrm{m}$ is selected to start at a particular frequency.

The assumptions made that only mode $m$ and mode $m-1$ are active at a frequency, that a correct particular frequency can be selected for a mode to cut-on, and that the pressure wave is stationary and not spinning are not perfectly valid. In addition, the measured cross-spectrum required as input to the two equations is experimentally determined and subject of nominal experimental error and statistical uncertainties. Also, the measured auto-spectrum includes random noise in addition to coherent signals from propagating waves. Consequently, a solution method that provides an optimum solution in a least squares sense without derivatives was used. Algorithms for minimization without derivatives are discussed by Brent. ${ }^{33}$ The search technique used in this study is described by Powell ${ }^{34}$ and Fortran computer code is given in Shapiro ${ }^{35}$ and Kuester $^{36}$. The code used was a modified version of the one given by Shapiro ${ }^{35}$ which was updated to be in a FORTRAN 90 style. The cost function used is written in terms of sound pressure level and phase angle. We have

$$
\begin{aligned}
& L_{0 \theta}(f)=10 \log _{10}\left(\left|\overline{G_{0 \theta}(f)}\right|^{2}\right) \\
& L_{x x}(f)=\min \left[10 \log _{10}\left(\left|\overline{G_{11}(f)}\right|^{2}\right), 10 \log _{10}\left(\left|\overline{G_{22}(f)}\right|^{2}\right)\right] \\
& H_{0 \theta}(m, f)=10 \log _{10}\left(\left.\overline{\mid P_{0} P_{\theta}^{*}\left(A_{m}(f), A_{m-1}\right)}\right|^{2}\right)+20 \log _{10}\left(p_{k}\right) \\
& H_{00}(m, f)=10 \log _{10}\left(\left.\overline{\mid P_{0} P_{0}^{*}\left(A_{m}(f), A_{m-1}\right)}\right|^{2}\right)+20 \log _{10}\left(p_{k}\right) \\
& \phi_{0 \theta}(m, f)=\overline{\phi_{0 \theta}\left(A_{m}(f), A_{m-1}(f)\right)} \\
& C 1(f)=\left[L_{0 \theta}(f)-H_{0 \theta}(m, f)\right]^{2} \\
& C 2(f)=\left\{\begin{aligned}
0 & : \quad H_{00}(m, f) \leq L_{x x}(f) \\
{\left[L_{x x}(f)-H_{00}(m, f)\right]^{2} } & : \quad H_{00}(m, f)>L_{x x}(f)
\end{aligned}\right.
\end{aligned}
$$




$$
\begin{aligned}
C 3(f) & =\left\{\begin{array}{cll}
\min \left[\left(\bar{\phi}_{0 \theta}(f)-360\right)^{2},\left(\bar{\phi}_{0 \theta}(f)-0.0\right)^{2}\right] & : & \\
\min \left[\left(\bar{\phi}_{0 \theta}(f)-360\right)^{2},\left(\bar{\phi}_{0 \theta}(f)-0.0\right)^{2}\right] & : & \text { if } \phi_{0 \theta}(m, f)=0 \\
\left(\bar{\phi}_{0 \theta}(f)-180\right)^{2} & : & \text { if } \phi_{0 \theta}(m, f)=360
\end{array}\right. \\
C & =C 1(f)+1000 C_{2}(f)+C_{3}(f)
\end{aligned}
$$

where

$$
p_{k}=\frac{10^{(171 / 20)}}{0.25}
$$

and Eq. ( 32 ) defines artificial constraint $\mathrm{C} 3$ which limits the magnitude of the auto-spectrum calculated with the restricted modal model and insures that it is near the measured auto-spectrum. The mode spans shown in table 2 on page 12 indicates cutoff frequencies selected. They correspond to those discussed in Appendix A. The same table is used for all test conditions.

\section{Results}

\section{A. Reconstruction of Measured Data}

The first measure of the extent the restricted modal model implemented with numerical optimization procedure yields an acceptable set of modal amplitudes is how well the coefficients reconstruct the measured cross-spectrum using Eqs.( 22 ), ( 23 ) and ( 24 ). Results are shown in Fig. 6 on page 22. It is clear that the procedure discussed is effective in finding a set of coefficients which can construct the measured amplitude and phase spectra.

A second measure of the extent the restricted modal model implemented with numerical optimization procedure yields an acceptable set of modal amplitudes is how well the coefficients reconstruct the measured auto-spectrum using Eq. ( 25 ). Results are shown in Fig. 7 on page 23 The measured auto-spectrum contains noise and should be larger than the reconstructed auto-spectrum. At frequencies less than $180 \mathrm{~Hz}$. where only the $m=0$ mode exists the results are quite good as expected. At higher frequencies the artificial constraint included in the minimization procedure is forcing the reconstructed auto-spectrum to be near the measured auto-spectrum.

\section{B. Model Content}

In order to characterize the model coefficients the modes are normalized by the maximum value. The normalized coefficients are shown in Fig. 8 on page 24.

The mode normalization coefficients are plotted in Fig. 9 on page 25. Fig. 9 on page 25 also shows linear curve fits to the normalization coefficients.

\section{Synthesized Cross-Spectra}

The normalized coefficients by mode number for all cases were studied. The uniformity of the plots lead to the idea that one could use the mean value of the coefficients to synthesize the cross-spectra at a range of angles and shaft rotation speeds. The mean was constructed using the first eight test conditions. Values for test conditions at $2304 \mathrm{rpm}$ (N1 CORR) and $2400 \mathrm{rpm}$ ( N1 Corr) were excluded.

Mean relative coefficients are shown in Fig. 10 on page 26.

\section{Discussion}

A new treatment of the modal decomposition of the pressure field in a PW4098 engine combustor as determined by two Kulite pressure measurements was developed. A new method using aligned and unaligned coherence measurements showed that Kulite data presented is valid. The treatment uses the procedure of analyzing pressure propagation in the combustor in the same manner that pressure propagation in a compressor or fan are analyzed. A similar procedure was used by Karchmer ${ }^{16}$ to analyze YF102 combustor coherence 
measurements made in a test stand and engine. This procedure for the operating conditions considered uses an analysis in terms of waves that propagate in modes such that for waves other than the plane wave the mode of propagation is determined by the condition that the frequency of the wave is greater than a cutoff frequency. This cutoff frequency is determined by an acoustic eigenvalue equation, wall boundary conditions, and a longitudinal boundary conditions that correspond to an infinite duct with no reflections. This type of analysis is completely different than one based on the use of duct modes which are solution of the acoustic eigenvalue equation, with duct wall boundary conditions and duct exit and entrance boundary conditions. The analysis provides evidence the peaks and dips in the measured auto-spectra and cross-spectra magnitudes are due to annular duct propagation modes rather than a fluctuating pressure generating mechanism.

The modal analysis also uses assumption made by Karchmer ${ }^{16}$ that equal amplitude circumferential clockwise and counter-clockwise pressure waves exist for each circumferential mode, $m$. However, for modes other than the plane wave the new part of the treatment is the assumption that there are distinct frequency bands in which the individual modes, including the plane wave mode, overlap such that if circumferential mode $m$ and circumferential mode $m-1$ are present than circumferential mode $m-2$ is not. Consequently, in the analysis used herein at frequencies above the first cut-off mode frequency, only pairs of circumferential modes are assumed present at each frequency. The measured data up to $800 \mathrm{~Hz}$. was reconstructed. The $m=0$ plane wave mode was used over the interval $[0,175]$ Hertz. The $m=0$ and $m=1$ annular modes were used over the interval $[188,328]$ Hertz. The $m=1$ and $m=2$ annular modes were used over the interval [340,539] Hertz. The $m=2$ and $m=3$ annular modes were used over the interval $[551,832]$ Hertz.

In agreement with results obtained previously by Karchmer, ${ }^{16}$ the results obtained herein indicate that for each circumferential mode, the $E_{m \mu}^{\sigma}$ function for the radial pressure distribution (see Appendix A) corresponds to the first root, $\mu=0$ which has the least radial variation from hub to tip. A new result discussed in Appendix A is that the successful use of the same modal span frequencies (see Table 2 and 3) over a range of operating conditions for this particular engine (PW4098) suggests that the temperature. T, and velocity, $v$, of the flow at each operating condition are related by $c^{2}-v^{2}=$ a constant where $\mathrm{c}$ is the speed of sound, $c=\gamma R T / M W$. This result is obtained since the mean flow is included in the derivation of the annular duct mode equations.

The comparison of these results for the PW4098 combustor mounted in the engine with similar results for the YF102 combustor in an engine and installed in a ducted test rig ( Karchmer ${ }^{16}$ )show many similarities in the pressure field since the pressure field for the PW4098 and the YF102 depends on the first few circumferential modes, $m=1, m=2, m=3 \ldots$ and the corresponding zeroth order radial modes $\mu=0$.

Since the YF102 combustor component test rig did not include any turbo machinery this fundamental structure of the pressure field seems to be independent of propagating pressure fields from either the compressor or turbine or difference tones created by interacting waves from the compressor and turbine. The fact that the energy distribution is in frequency bands with well defined spans (see Table 2 and 3) related to particular cut-off modes of propagation explains the occurrence of well defined bands in Fig. 4 where the aligned and unaligned coherence functions are presented.

The frequency span of the modes for this case does not resemble that in the YF102 since the PW4098 larger than the YF102 ( Karchmer ${ }^{16}$ ). The energy distribution in the plane wave mode and the first few circumferential modes is identified over a range of operating conditions. Due to the difference in size the energy distribution in the modes for the PW4098 is again different since the PW4098 is so much larger than the YF102 ( Karchmer $^{16}$ ). The model has two drawbacks. The first is the assumption that equal amplitude circumferential clockwise and counter-clockwise pressure waves exist for each circumferential mode. The phase angles shown in Fig 5 would be only $0^{\circ}, 360^{\circ}$, or $180^{\circ}$ if this was true. This assumption seems more valid for the YF102 data ( Karchmer $\left({ }^{16}\right.$ ). The second drawback is shown in Fig. 6 where the reconstructed auto-spectrum is far below the measured auto spectrum below $200 \mathrm{~Hz}$ where the plane wave propagates. Above $200 \mathrm{~Hz}$ the difference between the measured and reconstructed auto spectrum is not very large.

\section{Conclusions}

The treatment of the modal decomposition of the pressure field in a combustor as determined by two Kulite pressure measurements developed herein is in reasonable agreement with the measurements. It was applied to data from a Pratt \& Whitney PW4098 engine combustor over a range of engine operating conditions. The method works well for the plane wave mode (below $200 \mathrm{~Hz}$ ). The method gives meaningful results at higher frequencies. The method does show it is feasible to use the available measurements to produce a 
restricted modal model.

\section{A. Pressure Field in Annular Duct with Flow}

The pressure field, $p=p(r, \phi, z, t)$ of an ideal gas flowing in an annular duct formed by two concentric cylinders with inner radius, $r_{a}$ and outer radius, $r_{b}$, is a solution of the homogeneous wave equation with constant mean density and constant speed of sound.

$$
\frac{1}{\bar{c}^{2}} \frac{D^{2} p^{\prime}}{D t^{2}}-\nabla^{2} p^{\prime}=0
$$

where $\bar{c}$ is the mean acoustic speed, the space coordinates are $(r, \phi, z), t$ is time and $D / D t$ is the substantial derivative, $D / D t=\frac{\partial}{\partial t}+u \frac{\partial}{\partial t}$.

The combustor will be treated as a hard wall annular duct with a mean axial flow. Propagation of acoustic modes in an annular duct with no mean flow is discussed by several researchers. ${ }^{4,11,37}$ The mean axial velocity is included in a discussion of axial flow acoustic modes propagating in a cylinder by several researchers ${ }^{7,12-14,38,39}$ and in an annular duct by Envia ${ }^{40}$. Since mode propagation in a annular combustion duct with mean flow mean flow is has not been discussed a treatment is given herein.

Equation (35) in polar coordinates in three dimensions is

$$
\left[\frac{\partial^{2}}{\partial r^{2}}+\frac{1}{r} \frac{\partial}{\partial r}+\frac{1}{r^{2}} \frac{\partial^{2}}{\partial \phi^{2}}+\frac{\partial^{2}}{\partial z^{2}}-\frac{1}{\bar{c}^{2}}\left(\frac{\partial}{\partial t}+\bar{u} \frac{\partial}{\partial z}\right)\right] p=0
$$

This partial differential equation is converted into an ordinary differential equation if $\mathrm{p}$ is taken to be the sum of an oscillatory and constant pressure terms,

$$
p=p_{o}(\vec{x}, t)+p_{c} .
$$

The oscillatory pressure $p_{o}$ is separable into the product of a space-dependent and time-dependent function.

$$
p_{o}(\vec{x}, t)=P(\vec{x}) T(t)
$$

where we assume $T=T_{o} e^{i \omega t}$.

The space-dependent part, $P$, is the product three single-argument space functions,

$$
P(\vec{x})=R(r) \Phi(\phi) Z(z) .
$$

where the solutions are $\Phi(\phi)=\cos (\beta \phi)$ or $\Phi(\phi)=\sin (\beta \phi)$

and $\left.Z(z)=Z_{o} e^{i k \Omega}\right)$.

Using the convention that primes denote differentiation of a single argument function with respect to that argument, the wave equation becomes

$$
\left[\frac{R^{\prime \prime}}{R}+\frac{1}{r} \frac{R^{\prime}}{R}+\frac{1}{r^{2}} \frac{\Phi^{\prime \prime}}{\Phi}\right]+\frac{Z^{\prime \prime}}{Z}-\frac{1}{\bar{c}^{2}}\left(\frac{T^{\prime \prime}}{T}+2 \bar{u} \frac{T^{\prime}}{T} \frac{Z^{\prime}}{Z}+\bar{u}^{2} \frac{Z^{\prime \prime}}{Z}\right)=0
$$

or

$$
\begin{aligned}
{\left[\frac{R^{\prime \prime}}{R}+\frac{1}{r} \frac{R^{\prime}}{R}-\frac{1}{r^{2}} \beta^{2}\right]+\frac{Z^{\prime \prime}}{Z}-\frac{1}{\bar{c}^{2}}\left((-\omega)^{2}+2 \bar{u}(i \omega) \frac{Z^{\prime}}{Z}+\bar{u}^{2} \frac{Z^{\prime \prime}}{Z}\right) } & =0 \\
{\left[\frac{R^{\prime \prime}}{R}+\frac{1}{r} \frac{R^{\prime}}{R}-\frac{1}{r^{2}} \beta^{2}\right]+\left(\left(1-\bar{M}^{2}\right) \frac{Z^{\prime \prime}}{Z}-2 \bar{M} \frac{(i \omega)}{\bar{c}} \frac{Z^{\prime}}{Z}+\frac{\omega^{2}}{\bar{c}^{2}}\right) } & =0
\end{aligned}
$$

where $\bar{M}=\bar{u} \bar{c}$.

Now we define the wave number, $k=\omega / c$ and choose $(-\alpha k)^{2}$ as the constant equal to the $Z$-dependent group so that from Eq. (42)

$$
\left(1-\bar{M}^{2}\right) \frac{Z^{\prime \prime}}{Z}-2 \bar{M} \frac{(i \omega)}{\bar{c}} \frac{Z^{\prime}}{Z}+\frac{\omega^{2}}{\bar{c}^{2}}+(\alpha k)^{2}=0
$$


and

$$
\frac{R^{\prime \prime}}{R}+\frac{1}{r} \frac{R^{\prime}}{R}-\frac{1}{r^{2}} \beta^{2}-(\alpha k)^{2}+k^{2}=0
$$

We take as a solution to Eq. 43

$Z(z)=Z_{o} e^{i k \Omega z}$. Then

$$
\Omega^{2}-\frac{2 \bar{M}}{\left(1-\bar{M}^{2}\right)} \Omega-\frac{\alpha^{2}}{\left(1-\bar{M}^{2}\right)}=0
$$

Equation 45 has two solutions

$$
\begin{aligned}
& \Omega^{+}=\frac{\left[\bar{M}+\left[\bar{M}^{2}+\alpha^{2}\left(1-\bar{M}^{2}\right)\right]^{1 / 2}\right]}{\left(1-\bar{M}^{2}\right)} \\
& \Omega^{-}=\frac{\left[\bar{M}-\left[\bar{M}^{2}+\alpha^{2}\left(1-\bar{M}^{2}\right)\right]^{1 / 2}\right]}{\left(1-\bar{M}^{2}\right)}
\end{aligned}
$$

We define a new eigenvalue, $a$, as

$$
a^{2}=k^{2}\left(1-\alpha^{2}\right) r_{b}^{2}
$$

where $r_{b}$ is the outer radius. Then Eq. (44) becomes

$$
R^{\prime \prime}+\frac{1}{r} R^{\prime}+\left[\frac{a^{2}}{r_{b}^{2}}-\frac{\beta^{2}}{r^{2}}\right] R=0
$$

This is Bessel's differential equation with an eigenvalue, $a / r_{b}$. Solutions are Bessel functions of the first kind, $J_{\beta}\left(a r / r_{b}\right)$, and Bessel functions of the second kind $Y_{\beta}\left(a r / r_{b}\right)$ which are discussed in Abramowitz. ${ }^{41}$

The space dependence of the pressure is $P(r, \psi, x)=R(r) \Psi(\psi) Z(x)$ where

$$
\begin{aligned}
R(r) & =C_{1} J_{\beta}\left(a r / r_{b}\right)+C_{2} Y_{\beta}\left(a r / r_{b}\right)=C_{1}\left[J_{\beta}\left(a r / r_{b}\right)+Q_{\beta} Y_{\beta}\left(a r / r_{b}\right)\right] \\
& =C_{1} E_{\beta}\left(a r / r_{b}\right) \\
\Phi(\phi) & =C_{3} \sin (\beta \phi)+C_{4} \cos (\beta \phi) \\
Z(z) & =C_{5} e^{i k \Omega^{+}}+C_{6} e^{i k \Omega^{-}}
\end{aligned}
$$

The constants are evaluated by

- Applying boundary conditions.

- Requiring the pressure to be a continuous unique function of position.

- Requiring the pressure to be finite everywhere.

The wall boundary conditions are determined next. In terms of acoustic velocity, $\vec{u}$, where

$$
\rho \frac{\partial \vec{u}}{\partial t}=-\nabla p
$$

If the normal velocity vanishes at the boundary so does the normal acceleration. Consequently

$$
\left.(\nabla p)_{n}\right|_{b}=0
$$

On the walls the normal velocity is zero. Thus since if $\vec{u}$ is zero so is $\left.\vec{u}\right|_{n}$ we have $R^{\prime}(r)=0$ on the walls. As a consequence on the wall of the inner shell $\left(r=r_{a}\right)$ and the outer shell $\left(r=r_{b}\right)$ a pressure antinode is set. A pressure node is a region in which the air pressure is constant. A pressure anti-node (loop) is a region where the pressure is not constant.

Thus 


$$
\begin{aligned}
R^{\prime}(r) & =0, & & \left(r=r_{a}, r_{b}\right) \\
\frac{1}{r} \Phi(\phi)^{\prime} & =0, & & (\phi=0,2 \pi)
\end{aligned}
$$

From equation (52) and (57)

$$
\frac{1}{r}\left[\beta C_{3} \cos (\beta \phi)-\beta C_{4} \sin (\beta \phi)\right]=0, \quad(\phi=0, \phi=2 \pi)
$$

Then $C_{3}=0$ and $\beta=m$ where $m$ is the angular index and $m=0,1,2 \ldots$

From Eqs. ( 51 ) and ( 56 )

$$
\begin{aligned}
C_{1} \frac{a}{r_{b}} J_{m}^{\prime}\left(a r / r_{b}\right)+C_{2} \frac{a}{r_{b}} Y_{m}^{\prime}\left(a r / r_{b}\right) & =0 \quad r=r_{a}, r_{b} \\
Q_{m} & =-\frac{C_{2}}{C_{1}}=\frac{J_{m}^{\prime}\left(a r_{a} / r_{b}\right)}{Y_{m}^{\prime}\left(a r_{a} / r_{b}\right)} \\
& =\frac{J_{m}^{\prime}(a)}{Y_{m}^{\prime}(a)} \\
\frac{J_{m}^{\prime}\left(a r_{a} / r_{b}\right)}{J_{m}^{\prime}(a)} & =\frac{Y_{m}^{\prime}\left(a r_{a} / r_{b}\right)}{Y_{m}^{\prime}(a)}
\end{aligned}
$$

If the duct has no inner boundary, then $r_{a}=0$ and the boundary condition requires that $C_{2}$ in Eq. 51 be zero, since $Y_{\beta}(0)=-\infty$. Then Eq. 51 becomes

$$
R(r)=C_{1} J_{m}\left(a r / r_{b}\right)
$$

The boundary wall condition yields $J_{m}\left(a_{m l}\right)=0 \quad$ when $r_{a}=0$.

Letting $\sigma=r_{a} / r_{b}$, the eigenvalues of the solution are given by the roots of

$$
\frac{J_{m}^{\prime}\left(a_{m \mu}^{(\sigma)} \sigma\right)}{J_{m}^{\prime}\left(a_{m \mu}^{(\sigma)}\right)}-\frac{Y_{m}^{\prime}\left(a_{m \mu}^{(\sigma)} \sigma\right)}{Y_{m}^{\prime}\left(a_{m \mu}^{(\sigma)}\right)}=0 \quad r \neq 0
$$

Using these values of $\left(a_{m \mu}^{(\sigma)}\right)$ values of $Q_{m \mu}^{(\sigma)}$ can be determined from Eq. 60 and the radial characteristic function of $r$ is $R(r) / C_{1}=J_{m}\left(a_{m \mu}^{(\sigma)} \frac{r}{r_{b}}\right)+Q_{m \mu}^{(\sigma)} Y_{m}\left(a_{m \mu}^{(\sigma)} \frac{r}{r_{b}}\right)=E_{m \mu}^{(\sigma)}\left(a_{m \mu}^{(\sigma)} \frac{r}{r_{b}}\right)$

From Eq. 48 the wave number $\alpha$ is

$$
\alpha= \pm \frac{1}{k} \sqrt{k^{2}-\frac{\left(a_{m \mu}^{(\sigma)}\right)^{2}}{r_{b}^{2}}}
$$

From Eq. (46) and Eq. (47) the axial propagating mode is

$$
Z(z)=Z_{o} e^{\frac{i z}{\left(1-M^{2}\right)}\left\{\bar{M} k \pm\left[k^{2}-\left(1-\bar{M}^{2}\right) \frac{\left(a_{m \mu}^{(\sigma)}\right)^{2}}{r_{b}^{2}}\right]^{1 / 2}\right\}}
$$

If $k^{2}$ is less than $\left(1-\bar{M}^{2}\right) \frac{\left(a_{m \mu}^{(\sigma)}\right)^{2}}{r_{b}^{2}}$, the traveling wave solution is attenuated with distance. From this relationship the frequency, $f$, of a propagating disturbance must be greater than $f_{\text {cutoff }}$ where

$$
\begin{aligned}
f_{\text {critical }} & =\frac{c}{2 \pi} \frac{\left(a_{m \mu}^{(\sigma)}\right)}{r_{b}} \\
f_{\text {cutoff } f}(\bar{M}) & =\sqrt{\left(1-\bar{M}^{2}\right)} f_{\text {critical }}
\end{aligned}
$$

The function $f_{\text {cutof } f}(\bar{M})$ varies slowly with $\bar{M}$ when $\bar{M}$ is low. For example, at $\bar{M}=0.6, f_{\text {cutoff }}=0.8 f_{\text {critical }}$. The reduction of the cutoff frequency by mean flow has been shown experimentally by Mason ${ }^{42}$ to follow Eq. 67 for Mach numbers less than 0.17 . 
Table 3. Cuttoff Frequencies $\left(T=1619.37^{\circ} \mathbf{K}, \sigma=0.66, r_{a}=0.558 \mathbf{m}, r_{b}=0.837 \mathbf{~ m}, c=806.7 \mathbf{~ m} / \mathbf{s e c}\right.$

\begin{tabular}{|l|l|l|r|r|}
\hline order $m$ & zero sequence number $\mu$ & $\left(a_{m \mu}^{(\sigma)}\right)$ & $f_{\text {cutoff }}=\frac{\left(a_{m \mu}^{(\sigma)}\right) c}{2 \pi r_{b}}, \mathrm{~Hz}$. & $Q_{m \mu}^{(\sigma)}$ \\
\hline \hline 1 & 0 & 1.207637 & 185.245 & -0.408810 \\
2 & 0 & 2.412094 & 370.003 & -0.348305 \\
3 & 0 & 3.610271 & 553.797 & -0.314771 \\
4 & 0 & 4.799250 & 736.181 & -0.270046 \\
5 & 0 & 5.976450 & 916.757 & -0.223789 \\
\hline
\end{tabular}

Table 3 shows, the eigenvalues, $\left(a_{m \ell}^{(\sigma)}\right), Q_{m \mu}^{(\sigma)}$, and the cutoff frequencies, $f_{\text {cutoff }}=\frac{\left(a_{m \mu}^{(\sigma)}\right) c}{2 \pi r_{b}}$ for the first five order modes and $\mu=0$ using $T=1619.37^{\circ} \mathrm{K}$ , $\sigma=0.66, r_{a}=0.558 \mathrm{~m}, r_{b}=0.837 \mathrm{~m}$, and $c=806.7 \mathrm{~m} / \mathrm{sec}$. These parameters produce a mode span chart similar the one shown in Table 2 on page 12 which is used in the procedure presented herein. These were calculated for $\bar{M}=0.0$. Note that these same frequencies can appear at other operating conditions if when the temperature is increased the flow also increases so that

$$
T=\frac{1619}{1-\bar{M}^{2}}
$$

This relationship is tabulated in table 4 .

In terms of temperature and velocity we have

Table 4. Operating temperature verses Mach number for constant mode cutoff frequencies

\begin{tabular}{|r|r|}
\hline$M$ & $T$ \\
\hline \hline 0.00 & 1619 \\
0.05 & 1623 \\
0.10 & 1635 \\
0.15 & 1656 \\
0.20 & 1686 \\
0.25 & 1726 \\
0.30 & 1779 \\
0.35 & 1845 \\
0.40 & 1927 \\
0.45 & 2030 \\
0.50 & 2159 \\
\hline
\end{tabular}

$$
\begin{aligned}
c_{2} \sqrt{1-\left(v_{2} / c_{2}\right)^{2}} & =c_{1} \sqrt{1-\left(v_{1} / c_{1}\right)^{2}} \\
c_{2}^{2}-v_{2}^{2} & =c_{1}^{2}-v_{1}^{2}=\Delta \\
T_{2} & =\frac{\sqrt{v_{2}^{2}+\Delta}}{\gamma R / M W}
\end{aligned}
$$

Consequently, at each operating point it appears that the combustor flow velocity and temperature are related by Eq. 71 .

Characteristic $E_{m \mu}^{(\sigma)}\left(a_{m \mu}^{(\sigma)} \frac{r}{r_{b}}\right)$ functions for radial pressure distributions are shown in Fig. 11 on page 27 for $\mu=0$ and $m=1,2,3,4$, and 5 . 


\section{References}

${ }^{1}$ Jeffrey Hilton Miles. Validating coherence measurements using aligned and unaligned coherence functions. AIAA-20061389, NASA/TM-2006-214113, January 2006.

${ }^{2}$ Jeffrey Hilton Miles. Aligned and unaligned coherence: A new diagnostic tool. AIAA-2006-0010, NASA/TM-2006-214112, January 2006

${ }^{3}$ Jeffrey Hilton Miles. Procedure for separating noise sources in measurements of turbofan engine core noise. AIAA-20062580, May 2006.

${ }^{4}$ J.M. Tyler and T.G. Sofrin. Axial flow compressor noise studies. Transactions SAE, 70 :309-332, 1962.

${ }^{5}$ Philip M. Morse and K. Uno Ingard. Theoretical Acoustics. McGraw-Hill Book Company, 1968.

${ }^{6}$ Ira Dyer. Measurement of noise sources in ducts. Journal of the Acoustical Society of America, 30 No. 9:833-841, September 1958.

${ }^{7}$ B. D. Mugridge. The measurement of spinning acoustic modes generated in an axial flow fan. J. Sound Vib., 10 No. 2:227-246, 19691969

${ }^{8}$ C.J.Moore. In-duct investigation of subsonic fan 'rotor alone' noise. Journal of the Acoustical Society of America, $\mathbf{5 1}$ No. 5:1471-1482, 1972 .

${ }^{9}$ Ulrich Bolleter and Malcolm J. Crocker. Theory and measurement of modal spectra in hard-walled cylindrical ducts. Journal of the Acoustical Society of America, 51 No. 5:1439-1447, 1972.

${ }^{10} \mathrm{P}$. Harel and M. Perulli. Measurement, in a duct, of the space-structure of the discrete-frequency noise generated by an axial compressor. Journal of Sound and Vibration, 23 No. 4:487-506, 1972.

${ }^{11} \mathrm{C}$. J. Moore. Measurement of radial and circumferential modes in annular and circular fan ducts. Journal of Sound and Vibration, 62 No. 2:235-256, 1979.

${ }^{12}$ E.J. Kerschen and J.P. Johnston. Modal content of noise generated by a coaxial jet in a pipe. Technical Report Stanford University JIAA TR-11,N80-33177, NASA-CR-163575, Stanford University Department of Aeronautics and Astronautics Stanford, California 94305, May 1978.

${ }^{13}$ E. J. Kerschen and J. P. Johnston. Modal content of noise generated by a coaxial jet in pipe. Journal of Sound and Vibration, 76 No. 1:95-115, 1981.

${ }^{14}$ E. J. Kerschen and J. P. Johnston. A modal separation measurement technique for broadband noise propagation inside circular ducts. Journal of Sound and Vibration, 76 No. 4:499-515, 1981.

${ }^{15}$ E. J. Kerschen and J. P. Johnston. Mode selective transfer of energy from sound propagation inside circular pipes to pipe wall vibration. J Acoust. Soc. Am., 67 No. 6:1931-1934, 1980.

${ }^{16}$ A. M. Karchmer. Acoustic modal analysis of a full scale annular combustor. AIAA Paper 83-0760, NASA TM-83334, 1983.

${ }^{17}$ Eugene A. Krejsa and Allen M. Karchmer. Acoustic modal analysis of the pressure field in the tailpipe of a turbofan engine. Technical Report NASA TM 83387, NASA, 1983.

${ }^{18}$ Edvard Grande. Exhaust noise field generated in the jt8d core engine- noise floor presented by the internal noise sources. J. Acoust. Soc. Am., 55 No.1:30-34, January 1974.

${ }^{19}$ Craig A. Wilson and James M. O'Connell. Yf102 in-duct combustor noise measurements with a turbine nozzle-final report volume 1. Technical Report NASA-CR-165562-Vol-1,LYC 81-32,N82-21031, Avco Lycoming Division, 1981.

${ }^{20}$ Craig A. Wilson and James M. O'Connell. Yf102 in-duct combustor noise measurements with a turbine nozzle-final report volume ii. Technical Report NASA-CR-165562-Vol-2,N82-21032, Avco Lycoming Division, 1981.

${ }^{21}$ Craig A. Wilson and James M. O'Connell. Yf102 in-duct combustor noise measurements with a turbine nozzle-final report volume iii. Technical Report NASA-CR-165562-Vol-3,N82-21033, Avco Lycoming Division, 1981.

${ }^{22}$ R. K. Matta, G. T. Sandusky, and V. L. Doyle. Ge core engine noise investigation program - low emission engines. Technical report, FAA Report No. FAA-RD-77-4, 1977.

${ }^{23}$ V. L. Doyle M. T. Moore. Core noise investigation of the cf6-50 turbofan engine. Technical Report R79AEG395, General Electric Company, Cincinnati, OH, Jan. 1980. NASA CR-159749.

${ }^{24}$ Edited by Bill Gunston OBE FRAeS. Jane's Aero-Engines. Jane's Information Group, September 2000. page 514.

${ }^{25}$ Samuel D. Stearns and Ruth A. David. Signal Processing Algorithms Using Fortran and C. PTR Prentice-Hall, Inc., 1993.

${ }^{26}$ Allan Piersol. Time delay estimation using phase data. IEEE Transactions on Acoustics, Speech, and Signal Processing, ASSP-29 No. 3:471-477, June 1981.

${ }^{27}$ Samuel D. Stearns and Don R. Hush. Digital Signal Analysis - Second Edition. Prentice-Hall, Inc., 1990.

${ }^{28}$ G. Clifford Carter. Receiver operating characteristics for a linearly thresholded coherence estimation detector. IEEE Transactions on Acoustics, Speech, and Signal Processing, ASSP-25:90-92, February 1977.

${ }^{29}$ G. Clifford Carter. Coherence and time dealy estimation. Proceedings of the IEEE, 75 No. 2:236-255, February 1987.

${ }^{30}$ DM Halliday, JR Rosenberg, AM Amjad, P Breeze, BA Conway, and SF Farmer. A framework for the analysis of mixed time series/point process data-theory and application to the study of physiological tremor. Prog. Biophys Mol Biol, 64 No.:237-278, 1995.

${ }^{31}$ David R. Brillinger. Time Series Data Analysis and Theory -Expanded Edition. Holden-Day, 1981. ISBN:0-8162-1150-7.

${ }^{32}$ Julius S. Bendat and Allan G. Piersol. Engineering Applications of Correlation and Spectral Analysis. John Wiley \&Sons, 1980.

${ }^{33}$ Richard P. Brent. Algorithms for Minimization Without Derivatives. Prentice-Hall,1973;Dover Pulications, 2002, 1973, 2002.

${ }^{34}$ M. J. D. Powell. An efficient method of finding the mibnimum of a function of several variables without calculating derivatives. Computer Journal, 7 No. 2:155-162, July 1964. 
${ }^{35}$ M. S. Shapiro and M. Goldstein. A collection of mathematical computer routines. Technical Report NYU-1480-14, New York University, February 1965.

${ }^{36}$ James L. Kuester and Joe H. Mize. Optimization Techniques with Fortran. McGraw-Hill, 1973.

${ }^{37}$ John W. Converse and Joe D. Hoffman. Acoustic standing waves in a rocket combustion chamber with ring and spoke baffles. Technical Report Report No. TM-67-5,N6818076,NASA CR-93262, Jet Propulsion Center Purde University Lafayette, Indiana, August 1967.

${ }^{38}$ M. L. Munjal. Acoustics of Ducts and Mufflers. John Wiley \& Sons, 1987. page 36-38.

${ }^{39}$ Walter Eversman. Theoretical models for duct acoustic propagation and radiation. In Harvey H. Hubbard, editor, Aeroacoustics of Flight Vehicles: Theory and Practice Volume 2: Noise Control, chapter 13. NASA, August 1991. pages101163.

${ }^{40}$ Edmane Envia. A High Frequency Model of Cascade Noise. Fourth Aerospace Conference cosponsored by the AIAA and the CEAS, Toulouse, France, June2-4 1998. NASA/TM-1998-208495, AIAA-98-2318.

${ }^{41}$ F. W. J. Olver. Bessel functions of integer order. In Milton Abramowitz and Irene A. Stegun, editors, Handbook of Mathematical Functions, chapter 9, pages 355-436. Dover Publications, 1964.

${ }^{42} \mathrm{~V}$. Mason. Some experiments on the propagation of sound along a cylindrical duct containing flowing air. J. Sound Vib., 10 No. 2:208-226, 1969. 

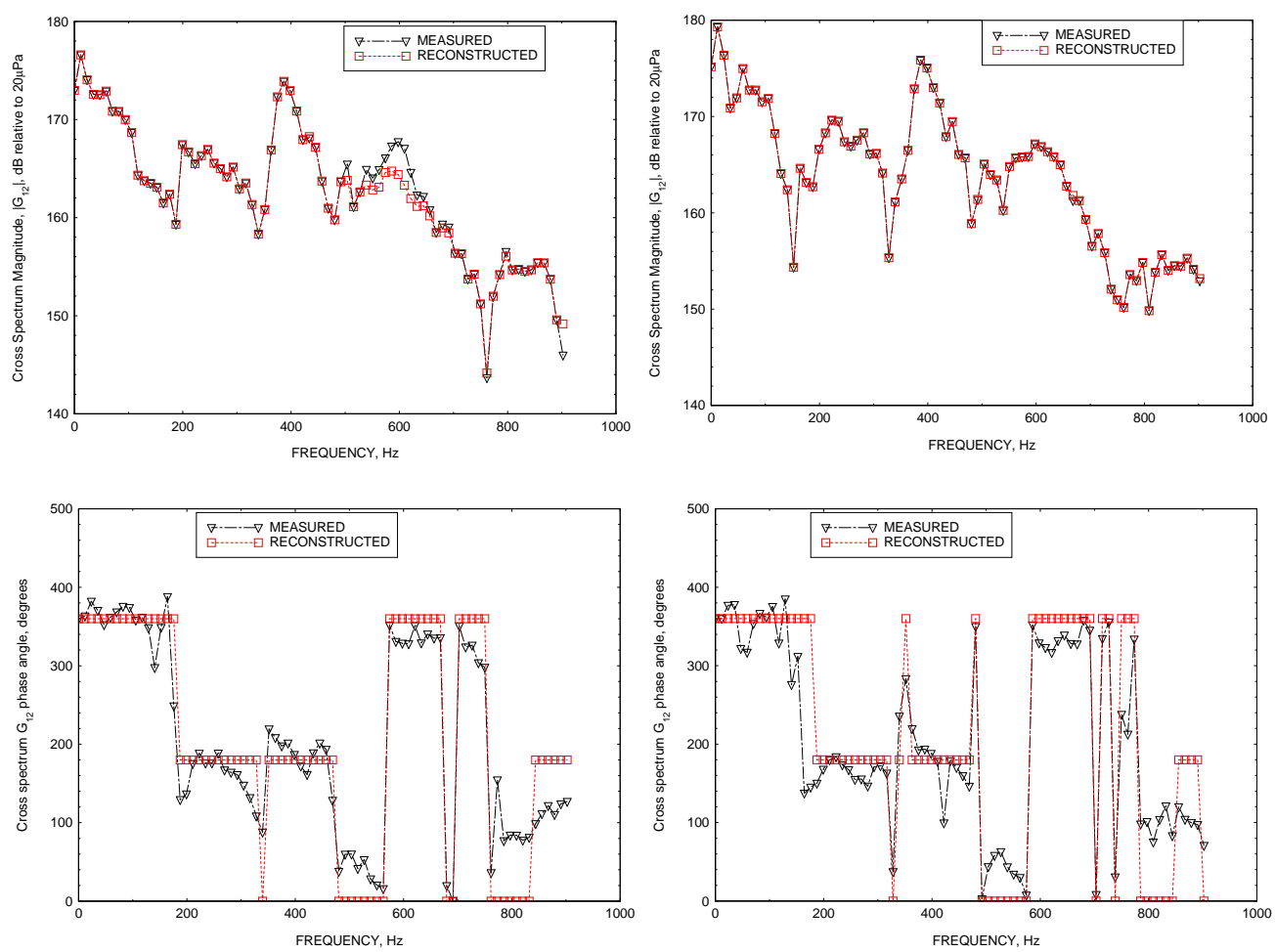

(a) $1622 \mathrm{rpm}$ ( N1 Corr )

(b) $1750 \mathrm{rpm}$ ( N1 Corr )
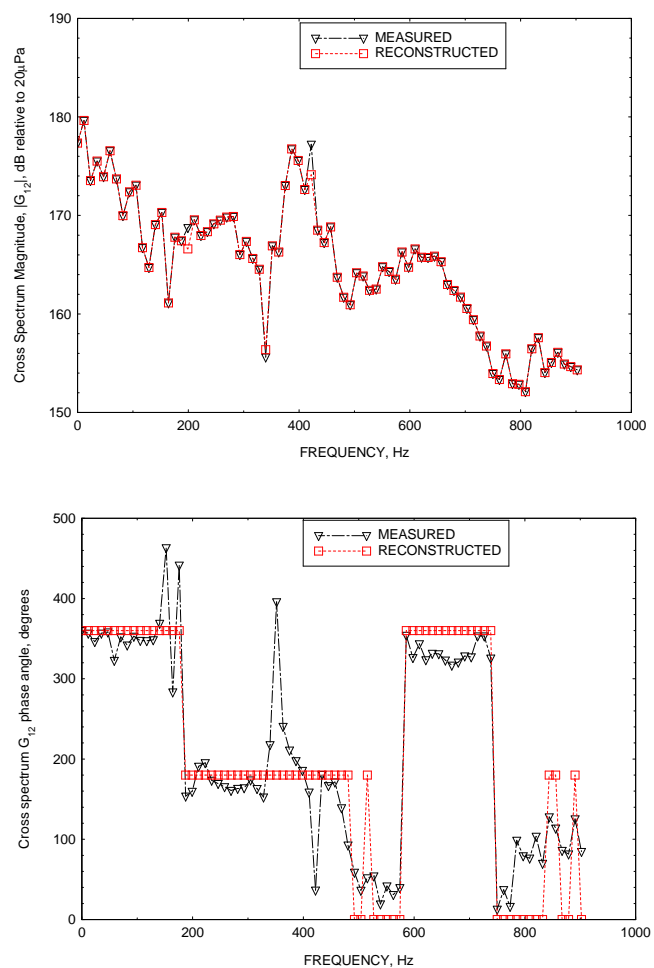

(c) $1900 \mathrm{rpm}$ ( N1 Corr )

Figure 6. Measured and reconstructed cross-spectrum. 


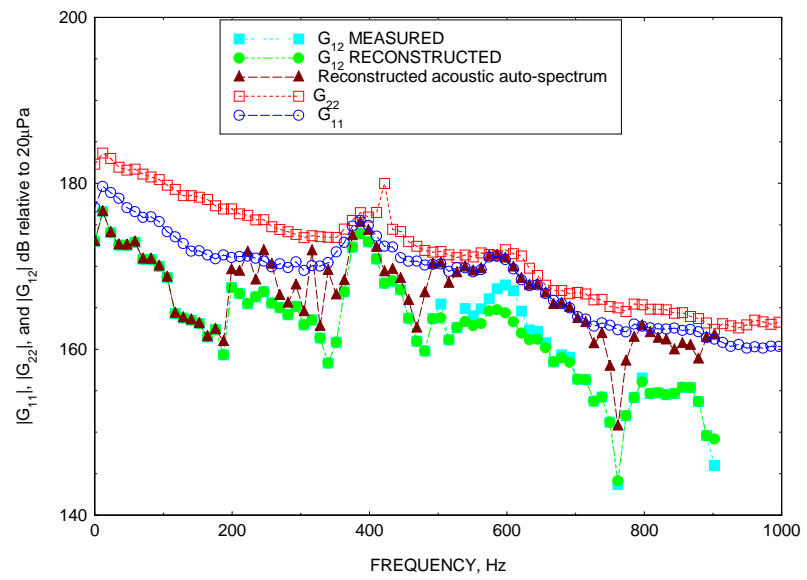

(a) $1622 \mathrm{rpm}$ ( N1 Corr )

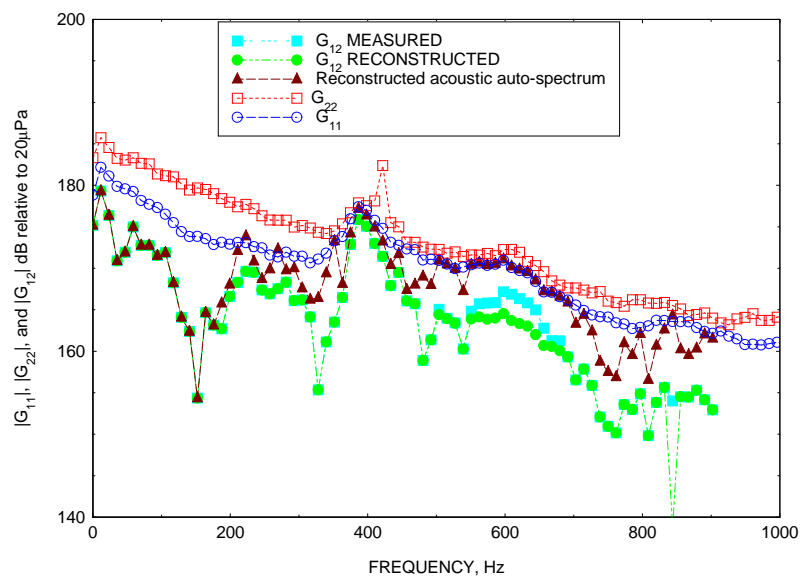

(b) $1750 \mathrm{rpm}$ ( N1 Corr )

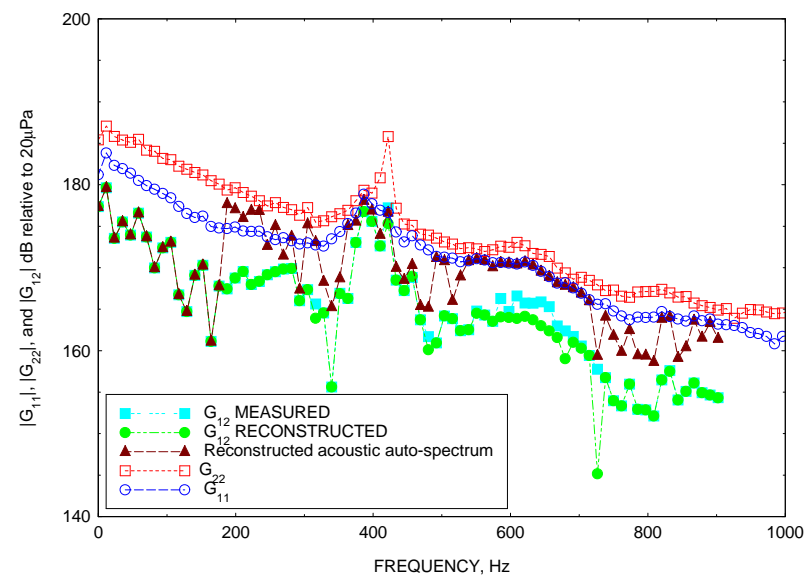

(c) $1900 \mathrm{rpm}$ ( N1 Corr )

Figure 7. Measured and reconstructed auto-spectrum and cross-spectrum magnitude. 


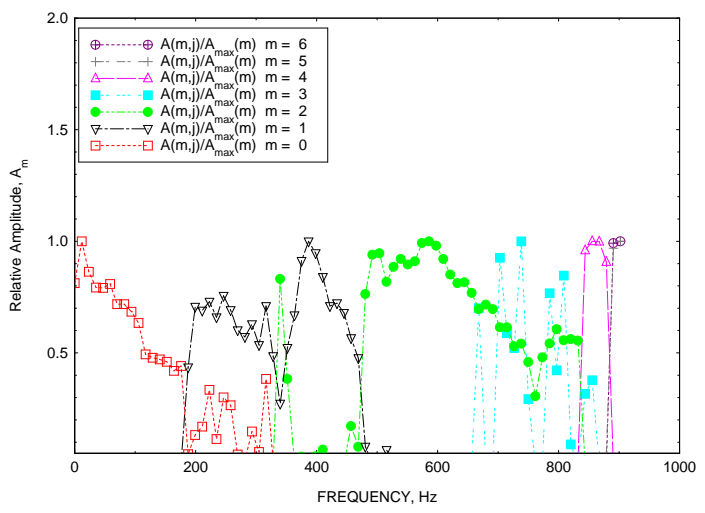

(a) $1622 \mathrm{rpm}$ ( N1 Corr )

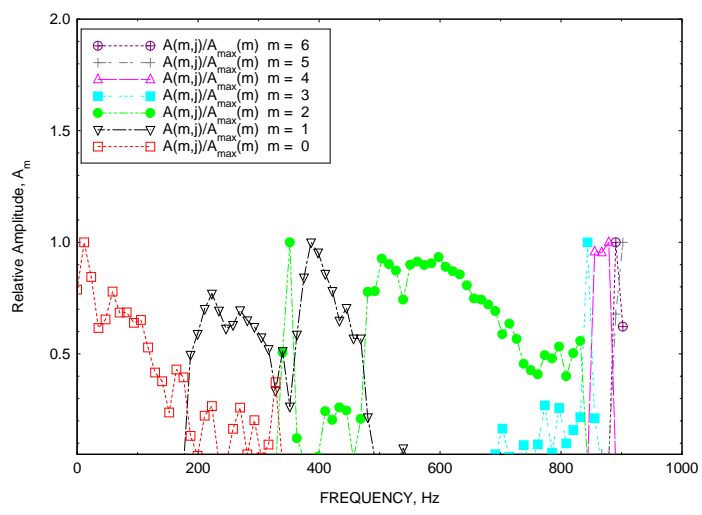

(b) $1750 \mathrm{rpm}$ ( N1 Corr )

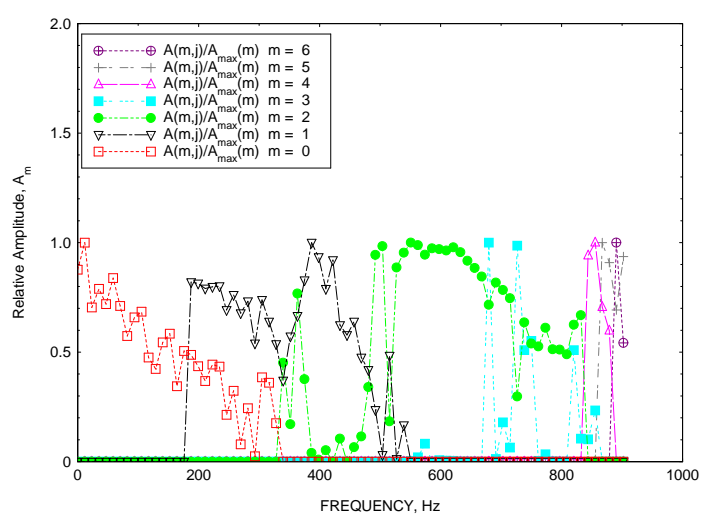

(c) $1900 \mathrm{rpm}$ ( N1 Corr )

Figure 8. Relative amplitudes, $A_{m}(f)=B_{m}(f)$. 


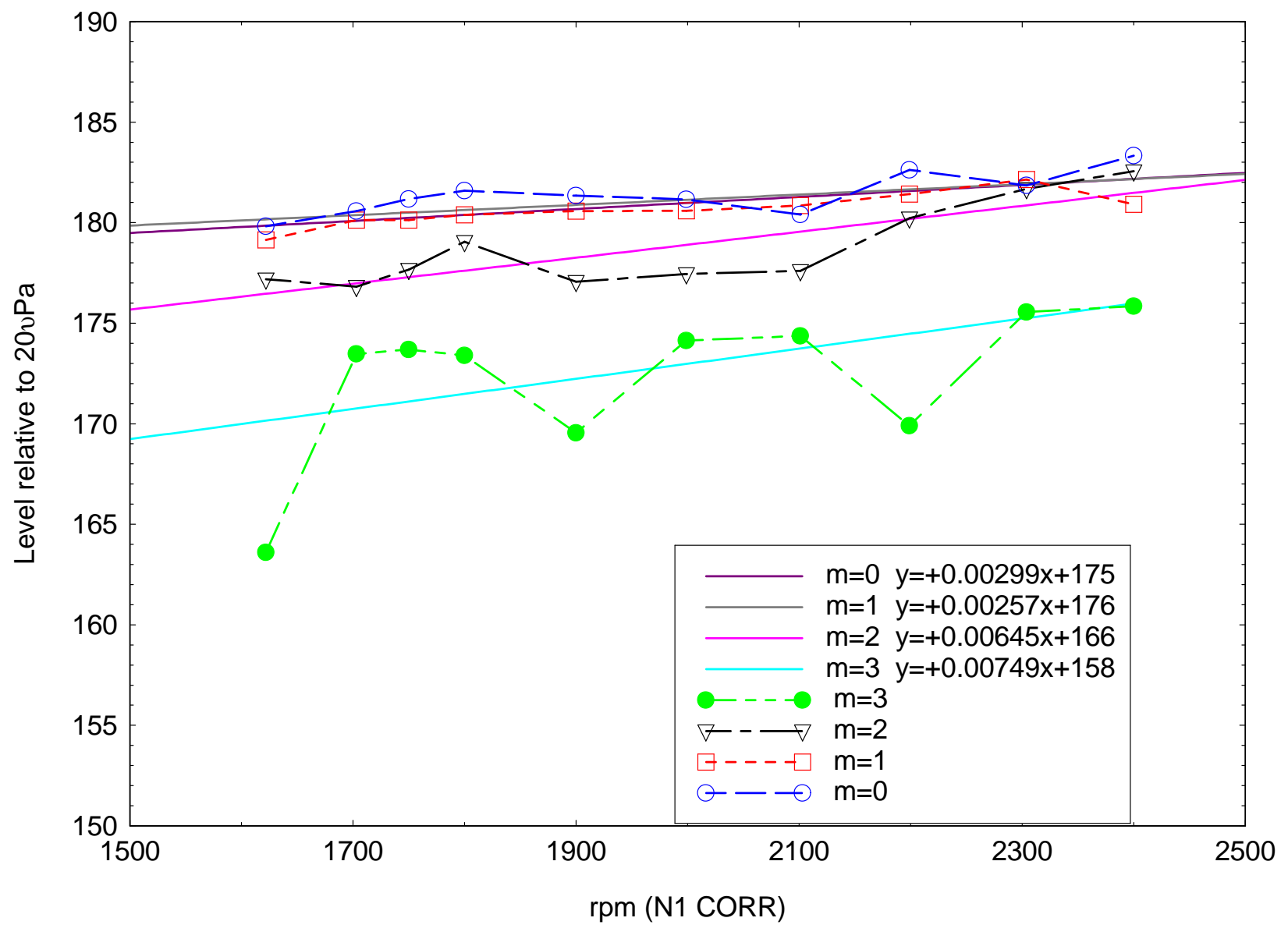

Figure 9. Mode normalization factors and linear curve fits. 


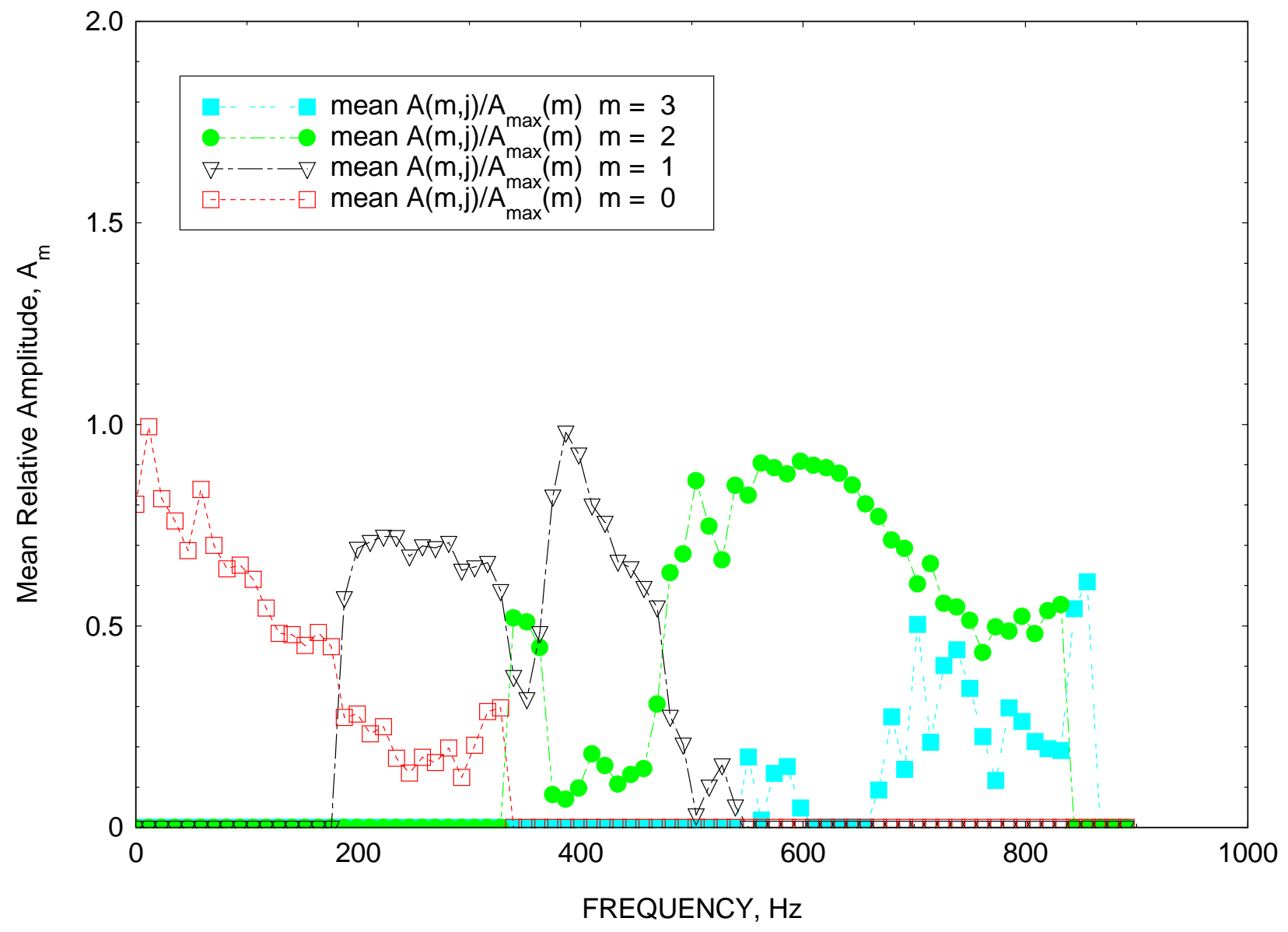

Figure 10. Mean relative amplitudes for $m=0, m=1, m=2$, and $m=3$. 


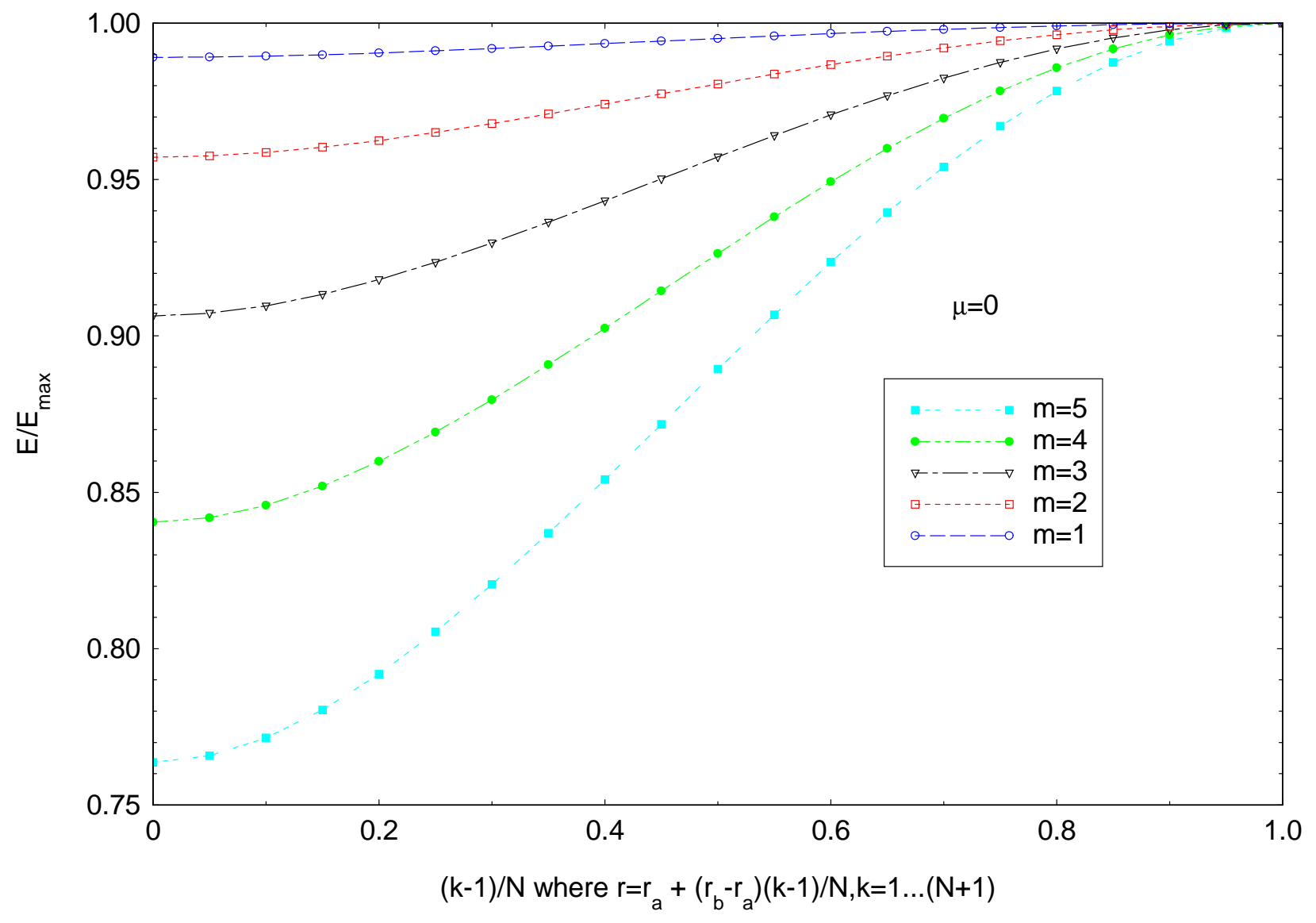

Figure 11. Characteristic $\mathbf{E}$ function for radial pressure fuunction for $\mu=0$ and $m=1,2,3,4$, and 5 . 


\begin{tabular}{|c|c|c|c|}
\hline \multicolumn{3}{|c|}{ REPORT DOCUMENTATION PAGE } & $\begin{array}{l}\text { Form Approved } \\
\text { OMB No. 0704-0188 }\end{array}$ \\
\hline \multicolumn{4}{|c|}{ 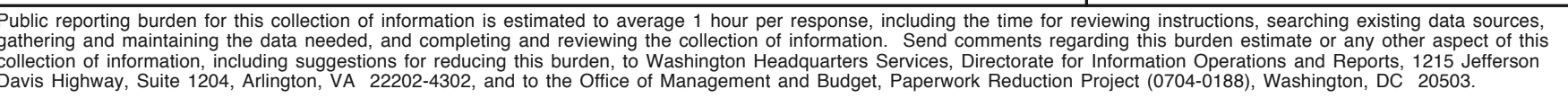 } \\
\hline 1. AGENCY USE ONLY (Leave blank) & $\begin{array}{l}\text { 2. REPORT DATE } \\
\text { May } 2006\end{array}$ & \multicolumn{2}{|c|}{$\begin{array}{l}\text { 3. REPORT TYPE AND DATES COVERED } \\
\text { Technical Memorandum }\end{array}$} \\
\hline \multicolumn{3}{|c|}{$\begin{array}{l}\text { 4. TITLE AND SUBTITLE } \\
\text { Restricted Acoustic Modal Analysis Applied to Internal Combustor Spectra and } \\
\text { Cross-Spectra Measurements }\end{array}$} & \multirow{2}{*}{$\begin{aligned} \text { 5. FUNDING NUMBERS } \\
\text { WBS } 561581.02 .08 .03\end{aligned}$} \\
\hline \multicolumn{3}{|l|}{$\begin{array}{l}\text { 6. AUTHOR(S) } \\
\text { Jeffrey Hilton Miles }\end{array}$} & \\
\hline \multicolumn{3}{|c|}{$\begin{array}{l}\text { 7. PERFORMING ORGANIZATION NAME(S) AND ADDRESS(ES) } \\
\text { National Aeronautics and Space Administration } \\
\text { John H. Glenn Research Center at Lewis Field } \\
\text { Cleveland, Ohio } 44135-3191\end{array}$} & $\begin{array}{l}\text { 8. PERFORMING ORGANIZATION } \\
\text { REPORT NUMBER } \\
\text { E-15626 }\end{array}$ \\
\hline \multicolumn{3}{|c|}{$\begin{array}{l}\text { 9. SPONSORING/MONITORING AGENCY NAME(S) AND ADDRESS(ES) } \\
\text { National Aeronautics and Space Administration } \\
\text { Washington, DC 20546-0001 }\end{array}$} & $\begin{array}{l}\text { 10. SPONSORING/MONITORING } \\
\text { AGENCY REPORT NUMBER } \\
\\
\text { NASA TM-2006-214351 } \\
\text { AIAA-2006-2581 }\end{array}$ \\
\hline
\end{tabular}

\begin{tabular}{|l|l}
\hline 12a. DISTRIBUTION/AVAILABILITY STATEMENT & 12b. DISTRIBUTION CODE \\
Unclassified - Unlimited & \\
Subject Category: 35 & \\
Available electronically at http://gltrs.grc.nasa.gov & \\
This publication is available from the NASA Center for AeroSpace Information, 301-621-0390. &
\end{tabular}

13. ABSTRACT (Maximum 200 words)

A treatment of the modal decomposition of the pressure field in a combustor as determined by two Kulite pressure measurements is developed herein. It is applied to a Pratt \& Whitney PW4098 engine combustor over a range of operating conditions. For modes other than the plane wave the new part of the treatment is the assumption that there are distinct frequency bands in which the individual modes, including the plane wave mode, overlap such that if circumferential mode $m$ and circumferential mode $m-1$ are present than circumferential mode $m-2$ is not. Consequently, in the analysis used herein at frequencies above the first cut-off mode frequency, only pairs of circumferential modes are individually present at each frequency. Consequently, this is a restricted modal analysis. A new result is that the successful use of the same modal span frequencies over a range of operating conditions for this particular engine suggests that the temperature, $T$, and the velocity, $v$, of the flow at each operating condition are related by $c^{2}-v^{2}=$ a constant where $c$ is the speed of sound.

\begin{tabular}{|c|c|c|}
\hline \multicolumn{3}{|c|}{ Combustion noise; Core noise } \\
\hline $\begin{array}{l}\text { 17. SECURITY CLASSIFICATION } \\
\text { OF REPORT } \\
\text { Unclassified }\end{array}$ & $\begin{array}{l}\text { 18. SECURITY CLASSIFICATION } \\
\text { OF THIS PAGE } \\
\text { Unclassified }\end{array}$ & $\begin{array}{l}\text { 19. SECURITY CLASSIFICATION } \\
\text { OF ABSTRACT } \\
\text { Unclassified }\end{array}$ \\
\hline
\end{tabular}



